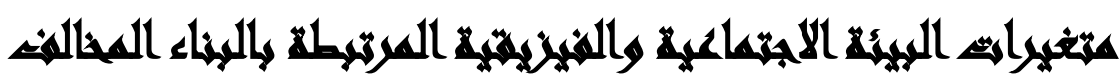

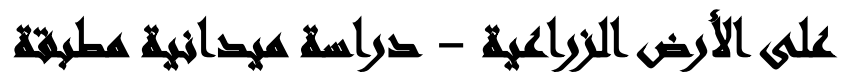

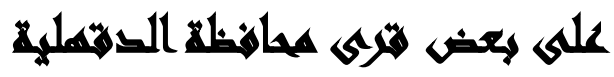

\section{[1.]}

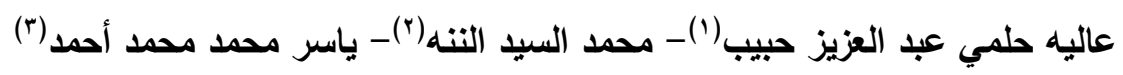

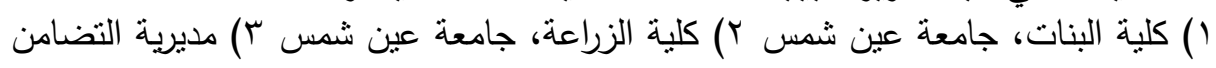

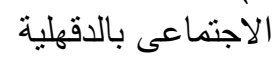

\section{المستخلس المئس}

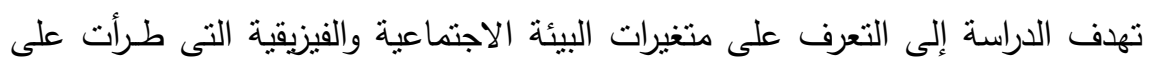

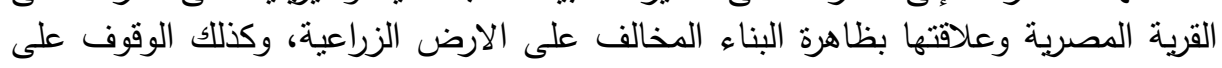

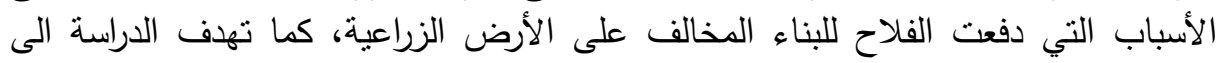

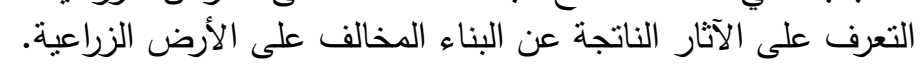

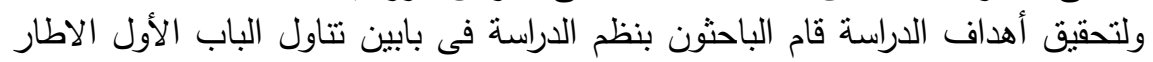

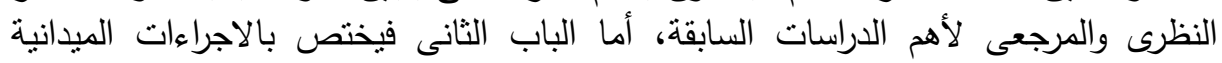

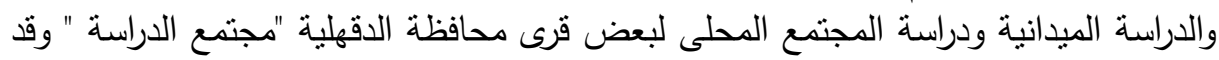

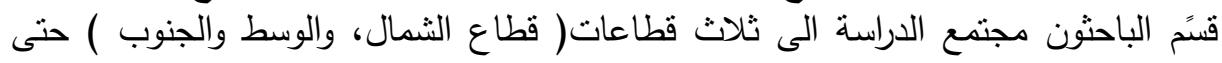

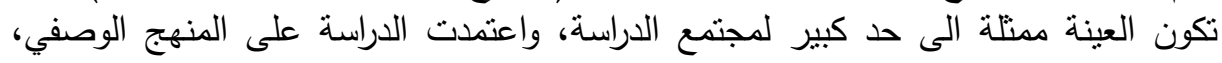

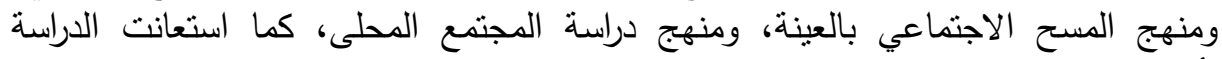

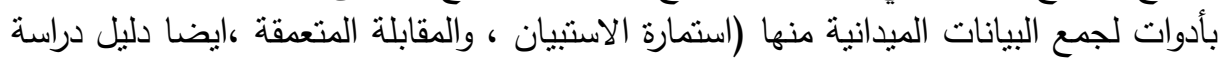

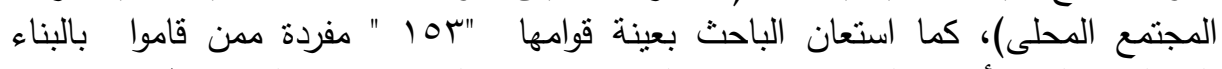

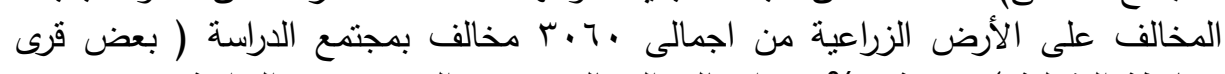

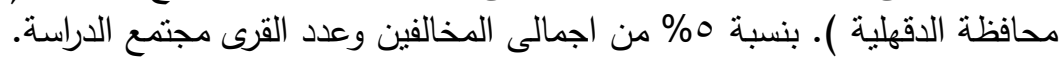
وتوصلت الاراسة إلى عدد من النت النتائج منها:

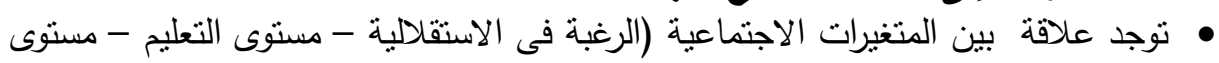

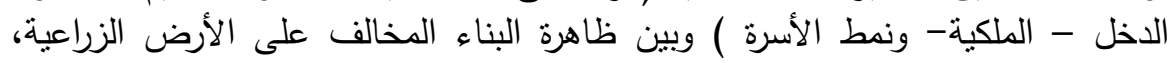

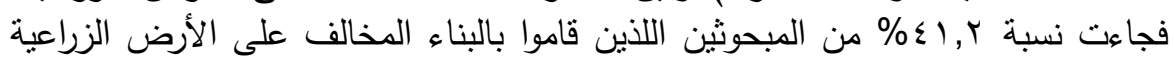

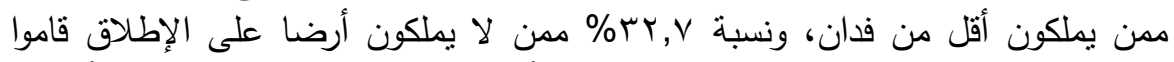

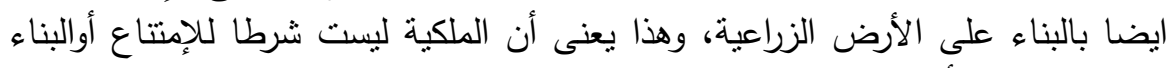
المخالف على الأرض الزراعية.

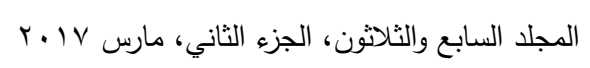


هاتوجد علاقة بين منغيرات البيئة الفيزيقية (نوع التربة - درجة الحرارة - وفرة مياة الرى )

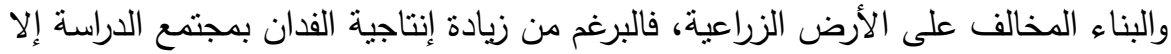

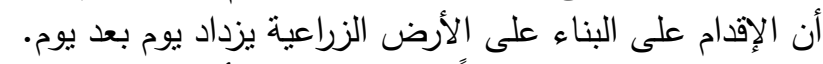

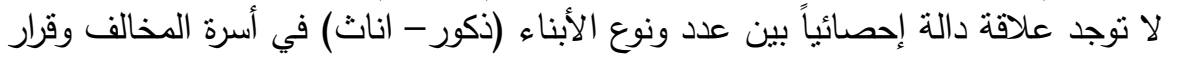

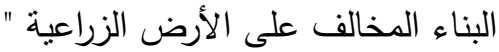

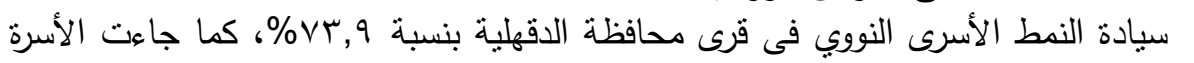

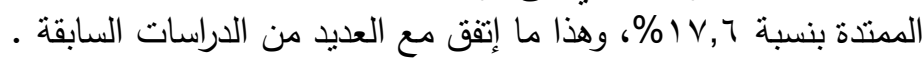

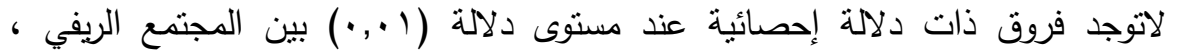

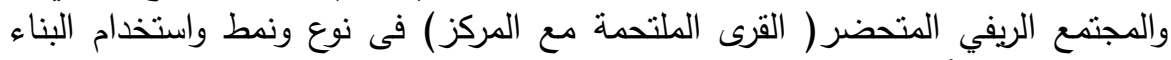
الذخالف على الأرض الزراعية.

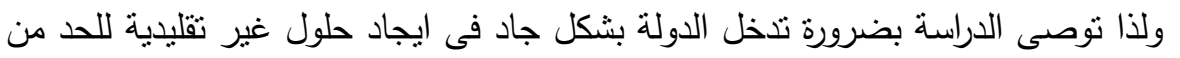

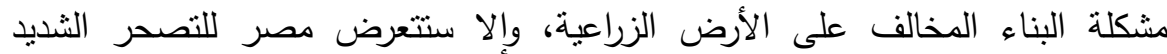

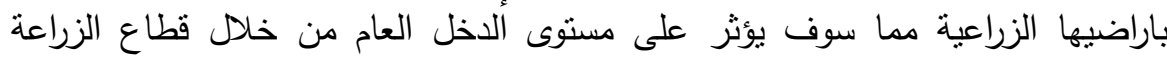
والذى يمنل الدخل الرئيس لمصر لكونها بلد زراعى لئى

\section{Ianatl}

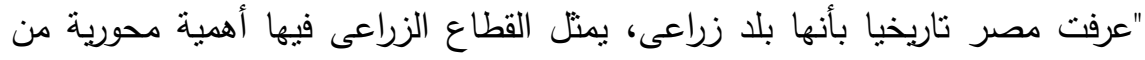

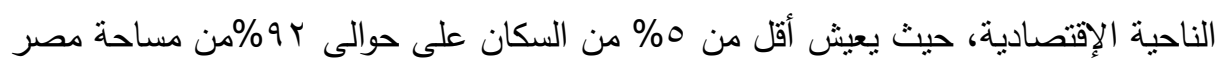

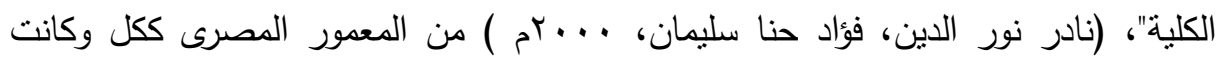

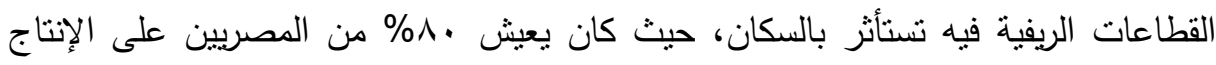

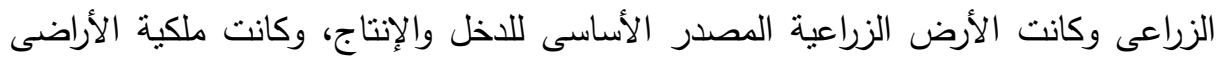

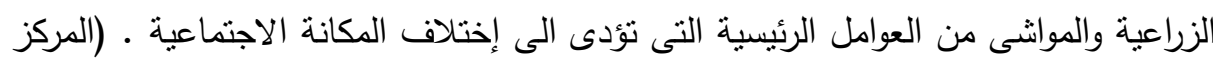

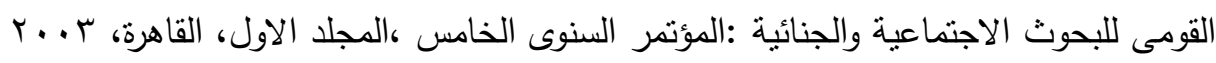

وتعانى مصر من العديد من المشاكل الاقتصادية والاجتماعية والفيزيقية والعمرانية ومن

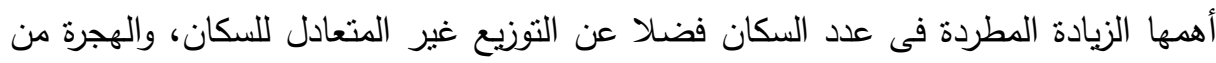
الريف إلى الحضر وظهور المناطق العشوائية فى المناطق الحضرية والريفية وزيادة الرقعة 
الأمر الذى يدعوا إلى الإهتمام بالدراسة الراهنة للوقوف على أهم المتغيرات الإجتماعية

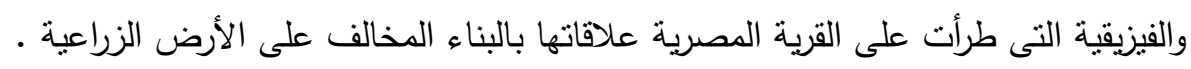

\section{x}

بالرغم من محدودية الارض الزراعية فى مصر وبالرغم من صدور العديد من القوانين

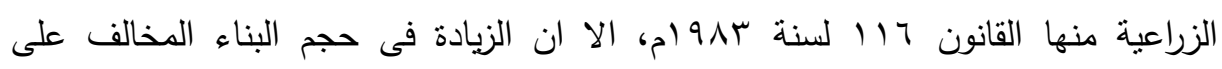

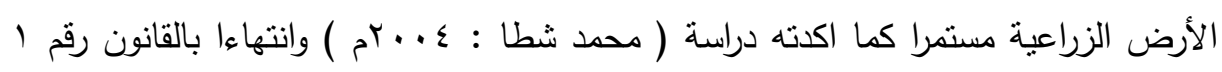

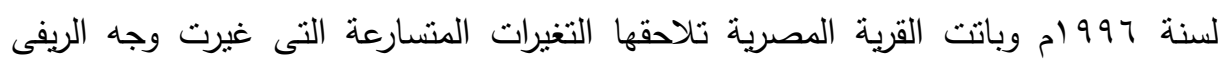
المصرى، فى البنيان الاجتماعى والقيم والعادات والتقاليد والثقافة فضلا عن التغيرات الفيزيقية

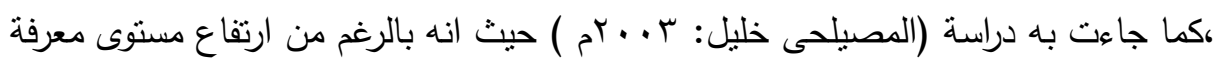

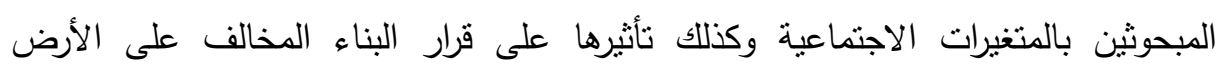

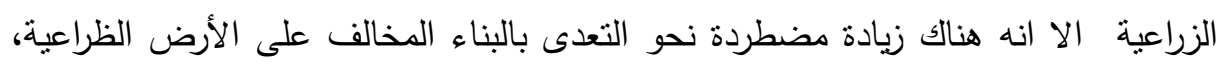

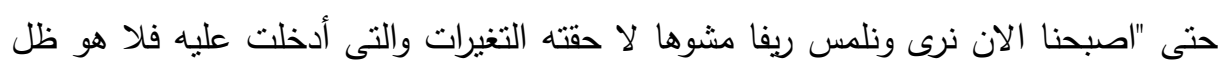

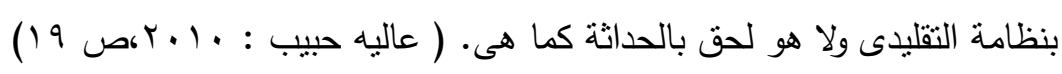
ويمكن تحديد مشكلة الدراسة الراهنة فى محاولة التعرف على الثى المتغيرات الاجتماعية

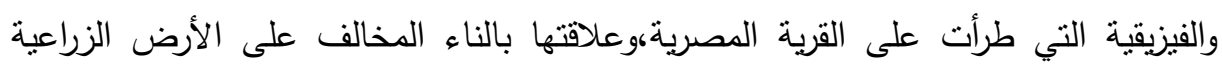

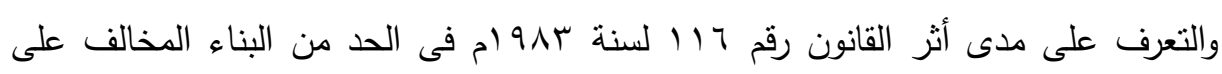

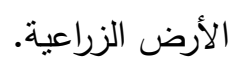

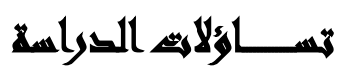

ما المتغيرات الاجتماعية التى طرأت على الريف المصريمن حيث (التعليم - نمط الاسرة

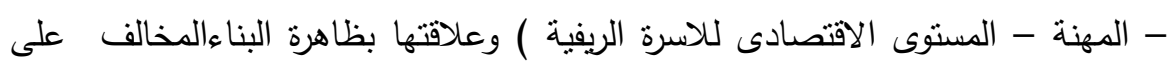

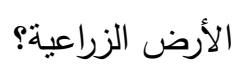

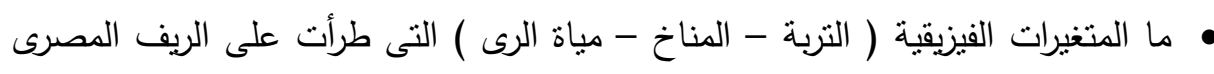
وعلاقتها بظاهرة البناء المخالف على الأرض الزراعية؟

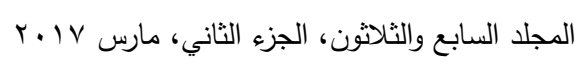


• ما مدى وجود علاقة بين صعوبة استخراج تراخيص البناء بالكتلة السكنية وظاهرة البناء

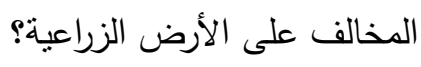

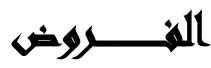

• توجد علاقة دالة إحصائياً بين الأبناء الذكور وحجم البناء المخالف على الأرض الزراعية.

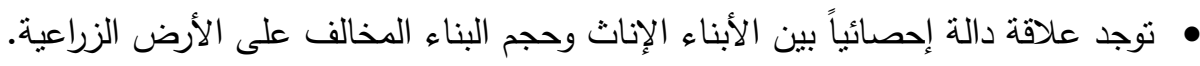

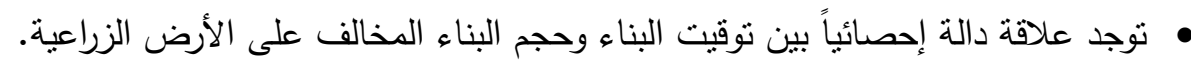

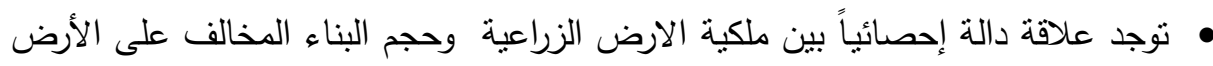

الزراعية.

• توجد علاقة دالة إحصائباً بين نمط الأسرة وحجم البناء المخالف على الأرض الزراعية .

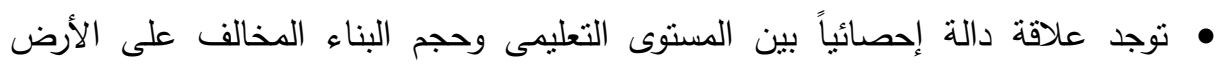
الزراعية. توجد علاقة دالة إحصائياً بين صعوبة إستخراج تراخيص البناء داخل الكتلة السكنية وحجم البناء المخالف على الأرض الزراعية.

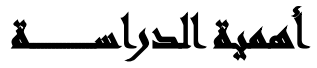

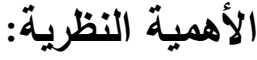

• تكمن الأهمية النظرية للدراسة فى إعتبارها محاولة لإثراء دراسات علم الاجتماع الريفى فى العى

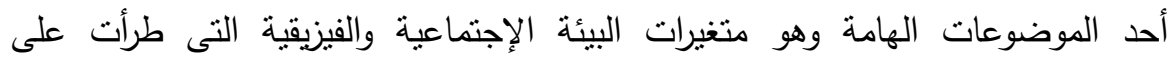
المجتمع الريفى المصرى وعلاقتها بظاهرة البناء المخالف على الأرض الزراعية، وخاصة الإسمة ولئه

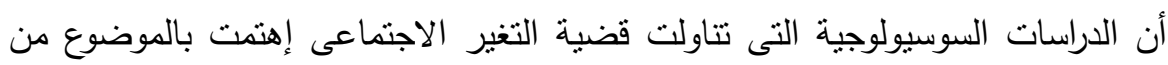
جوانب عديدة منها الجانب القانونى، من الجانب الاقتصادى، من الجانب المعرفى وعدم إنى

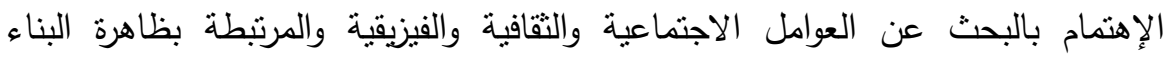

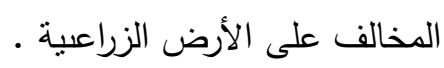


أيضا تكمن أهمية الدراسة فى تتناولها قضية مستقلة ولها أهميتها على المستوى الوطنى،

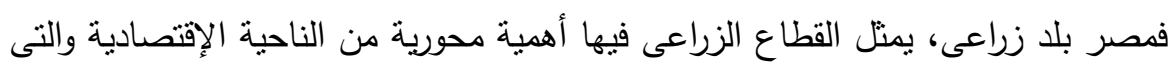

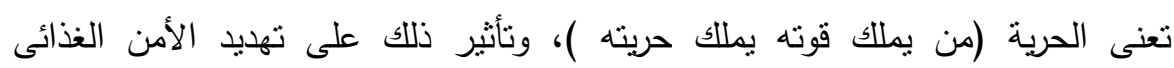
والإقتصاد الزراعلى فى مصر.

الأهمية التطبيقية: • تتمثل فيما تتوصل الية الدراسة الراهنة من نتائج تقدم رؤية واقعية لواقع الريف المصرى.

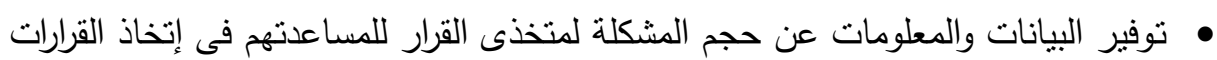
والإجراءات المناسبة للحد من ظاهرة التعدى على الأرض الزراعية.

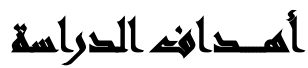

() التعرف على متغيرات البيئة الاجتماعية التى طرأت على الريف المصرى وعلاقتها بالبناءالمخالف على الارض الزراعية. r) التعرف على متغيرات البيئة الفيزيقية التى طرأت على البه الريف المصرى وعلاقتها بالبناءالمخالف على الارض الزراعية. r) وضع تصور للحد من البناء الدخالف على الأرض الزراعية.

\section{مهاهيهي التصواسم}

سوف يعرض الباحثُن للمفاهيم التالية : التغير الاجتماعى - التغير الفيزيقى

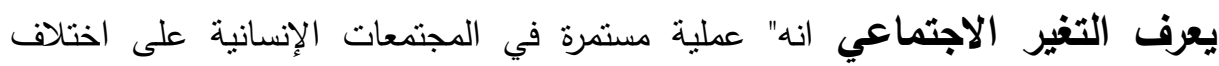

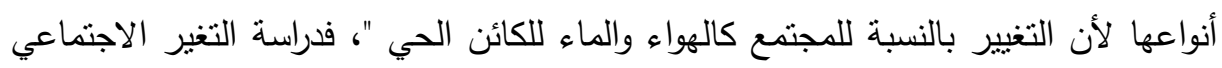

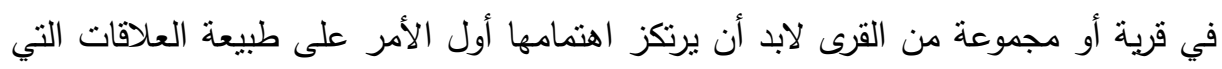
تربط القرويين بالأرض، والعلاقات الاجتماعية التي تقوم على هذه القاعدة وأهمها العائلة "

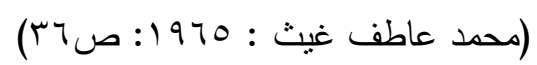


يمكن تعريف التغير الاجتماعى أيضا بأنه "المظهر الديناميكى للمجتمع الانسانى والحركة الاطرادية المستمرة المتتابعة التى تتم من خلال التفاعل الاجتماعى عبر الزمن، وتعبر عن انماط من العمليات والانتقال والتتمية والتقدم، وتتم عن الاختلافات والتعديلات

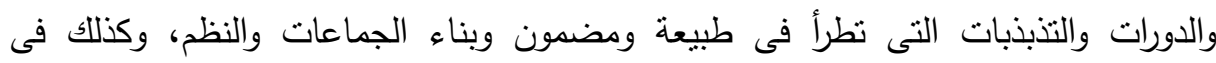

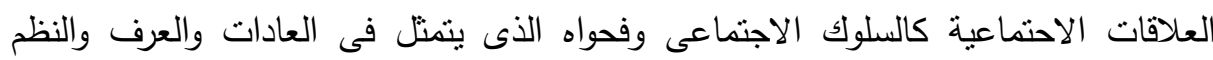
والقوانين واللغة خلال تتابع الزمن، وبحيث يمكن ملاحظتها وتقديريها. (حسين عبد الحميد ( Tr.

ويعرف ايضا بأنه يمثل الجانب المعياري " normative aspect " للحياة الاجتماعية أن كل المتمعات والثقافات تتغير دائما وباستمرار ولو أن بعضها يكون أسرع فى تغيره عن

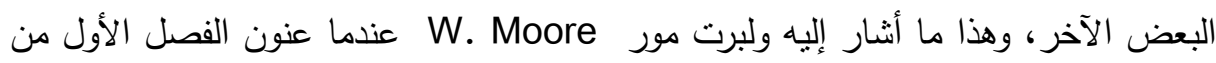

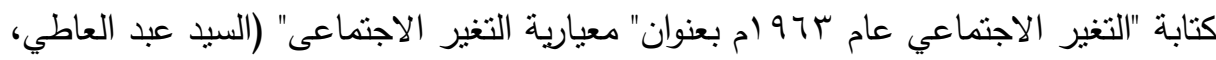

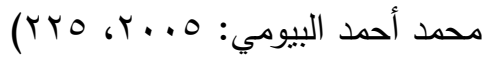
ويعرف ايضا بأنه " كافة أثكال التحول الجزئية أو الكلكلية التى نطرأ على البناء الاجتماعى - الثقافى لمجتمع من المجتمعات تحدث عبر سلسلة متصلة من العمليات

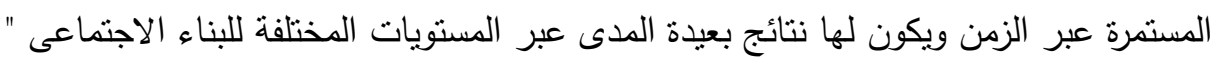

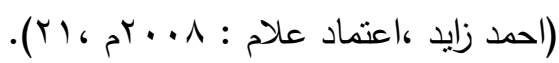
التعريف الإجرائي للتغير الاجتماعي الذى تتبناه الدراسة الراهنة: هو كل التغيرات المستمرة

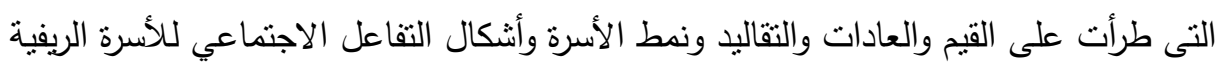
المصريــــــــة. ويمكن تعريف البيئة الفيزيقيــةة: إنها "عبارة عن الغلاف السطحي من الأرض اليابسة

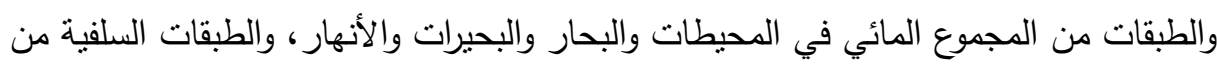

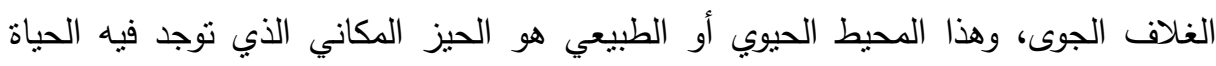
بأنماطها المتباينة وبما تشنمل عليه من الكائنات الحية، ومن مواد وقوى فاعلة ومؤثرة ، وهذه 
المنظومة سبقت ظهور المنظومة الاجتماعية والتكنولوجية بملايين السنين وهى عبارة عن

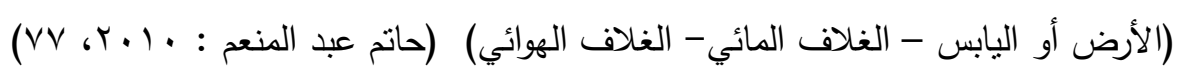

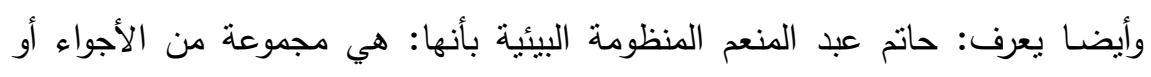

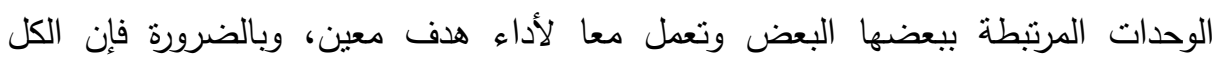

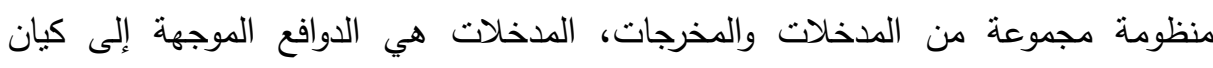
المنظومة هي الترجمة الفعلية لأهدافها، وقد تكون هذه الوحدات حية أو غير حية، وقد تكون مجرد انساق تجريدية منل المنظومة السياسية أو الاقتصادية.

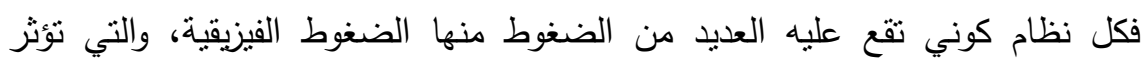

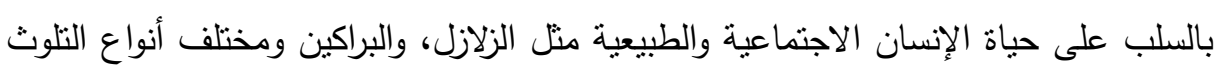

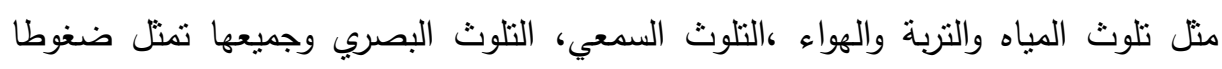

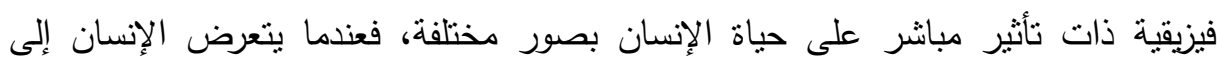

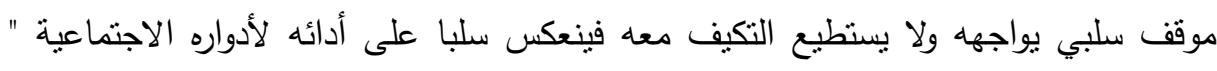

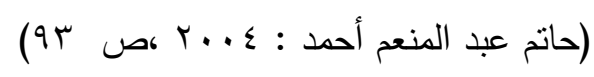
المتغيرات الفيزيقية: "هى تلك التغيرات التى تواجه دول العالم ( المتفدمة دنها والنامية ) والتى تعيق اى جهود مبذولة لتحقيق الاهداف الانمائية (التغير المناخى ) من خلال التأثير

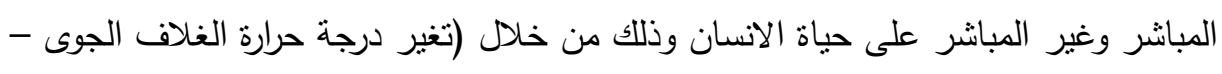

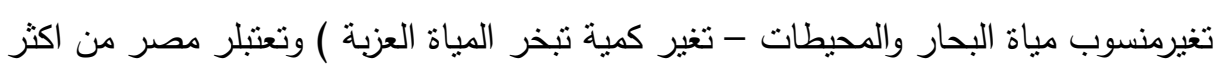

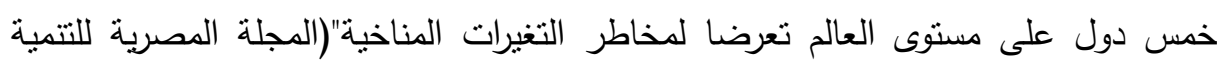

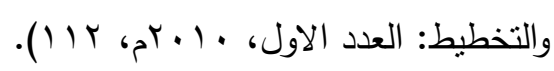
التعريف الإجرائي لمفهوم المتغيرات الفيزيقية: هى كل كل ما يرتبط بالأرض الزراعية (التربةالميـاه- الهواء - درجة الحرارة ).

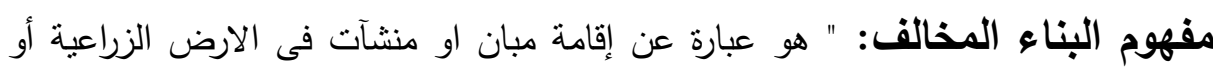

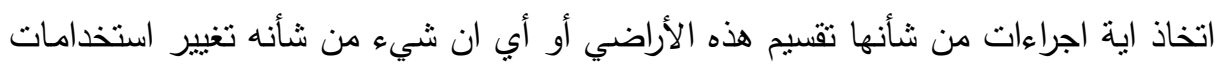

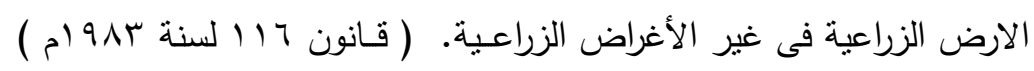


التعريف الإجرائي للبناء المخالف على الأرض الزراعية الذى نتبناه الدراسة الراهنة : " كل

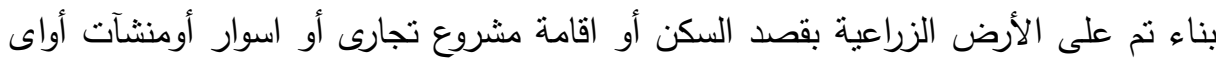

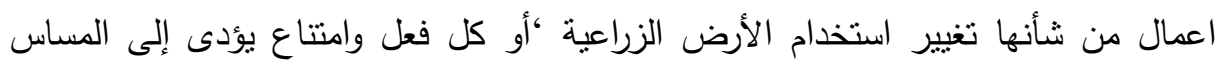

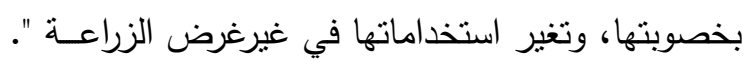

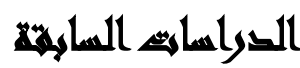

تمنلت الدراسات السابقة في محورين:

المحور الأول الاراسات التى تناولت متغيرات البيئة الاجتماعية والفيزيقية: 1- دراسة " مروة سامى السعيد با ـ rم بعنوان : متغيرات البيئة الاجتماعية والفيزيقية المرتبطة بثقافة الانتماء

هدفت الدراسة إلي: دراسة المتغيرات الثخصية وعلاقتها بثقافة الانتماء فى مجتمع شمال سيناء، الكثف عن اثر البيئة الاجتماعية والفيزيقية بمستوى ثقافة الانتماء.

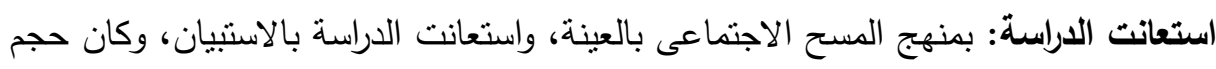

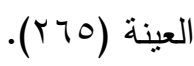

$$
\text { وتوصلت الاراسة الى اهم النتائجك }
$$

• أثثر العوامل الاجتماعية المختلفة على علية الانتماء برجع الى تمسك الفرد بالاسرة .

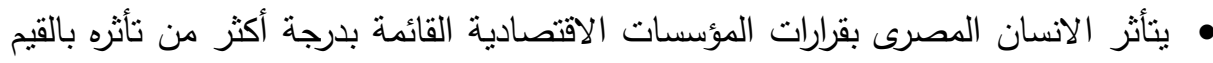

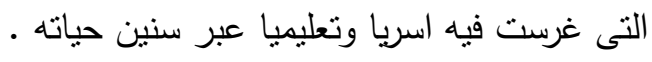

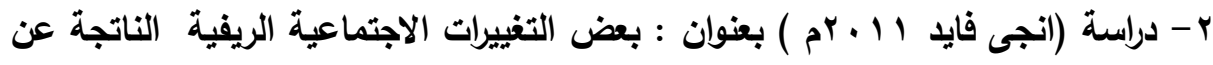

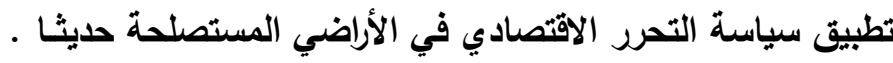

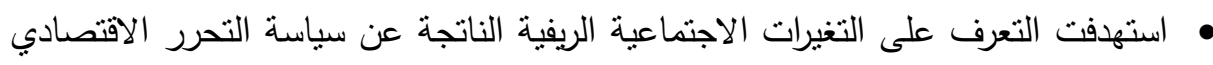

$$
\text { في قطاع الزراعة فى مجتمع الدراسة. }
$$
• التعرف على طبيعة الفروق بين كل من فترتى ماقبل وما بعد تطبيق سياسة التحرر الاقتصادى فى قطاع الزراعة، وذلك فيما يتعلق بعصرية المسكن كمتغير تابع.

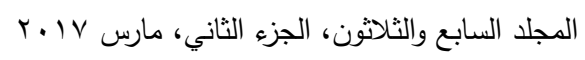


وتحقيقا لأهداف الدراسة: - مان

• استعانت الدراسة بمنهج القياس الاجنماعي وأجريت الدراسة بإحدى قرى محافظة البحيرة على عينة عشوائية بسيطة قوامها VT منتفعا من أعضاء جمعية أم صابر التعاونية الزراعية .

• ولقد استعانت الدراسة باستمارة الاستبيان من خلال المقابلة الشخصية كما استعانت

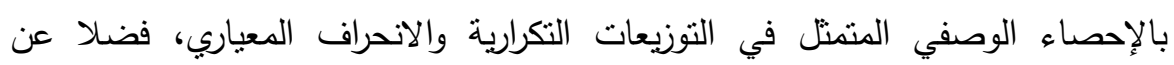
الإحصائي الاستدلال عن طريق استخدام اختيار الفروق بين منوسطي عينتين غير م سل لقياس شدة العلاقة الاقتراني paired-samples T Test مستقلتين. وقد أسفرت نتائج الاراسة: لا توجد فروق معنوية بين الفترتين بخصوص الارتباط الوجداني والتوسع بالبناء بالأرض الزراعية أي قبل وبعد التحرر الاقتصادي.

المحور الثاني: الدراسات التى تتاولت البناء المخالف على الارض الزراعية: تتاولت بعض الدراسات موضوع البناء على الارض الزراعية ومنها:

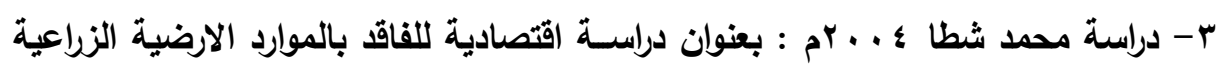
المصرية

استهدفت: دراسة الوضع الراهن لاقتصاديات الموارد الارضية الزراعية الدصرية، ومحاولة

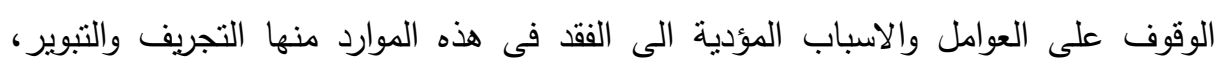

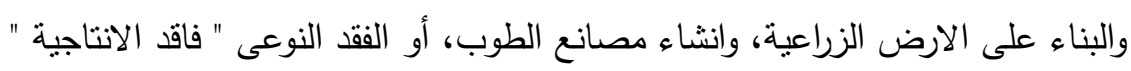
كما استعانت الاراسة: بالطرائق البحثية الإحصائية الوصفية، والتحليلية فى وصف التئف وتحليل بيانات الدراسة

\section{توصلت الدراسة الى بعض النتائج من أهمها:}

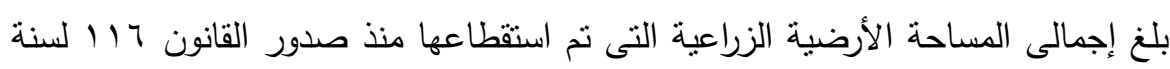

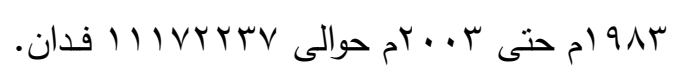

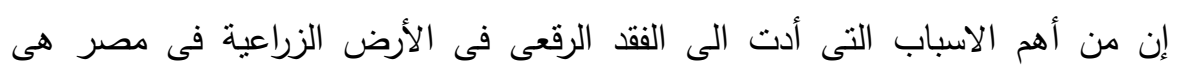

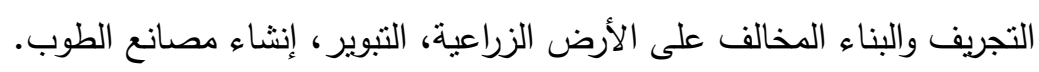




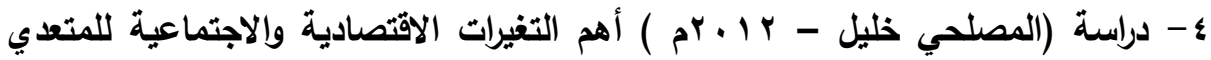
على الارض الزراعية بمحافظة الغربية

استهرفت الدراسة:

-التعرف على أهم المتغيرات الاجتماعية والاقتصادية المرتبطة بالتعدي على الأرض الزراعية

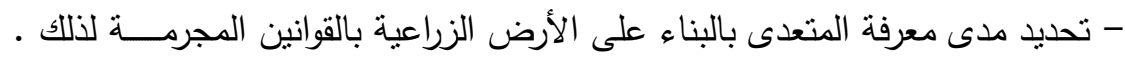

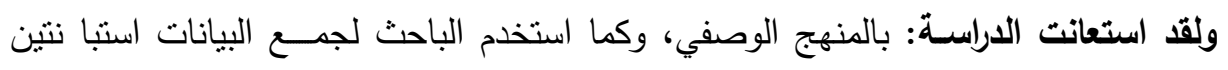

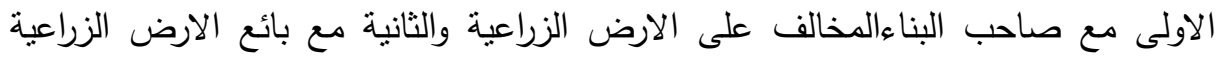

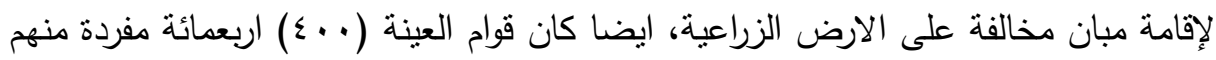

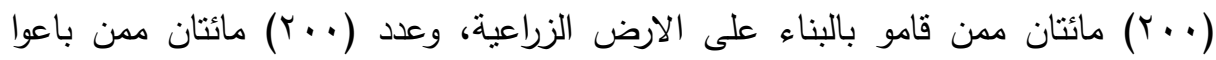

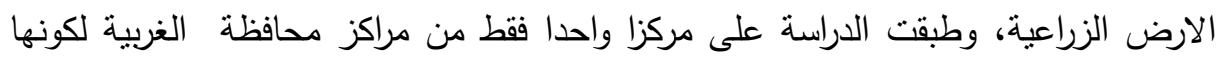

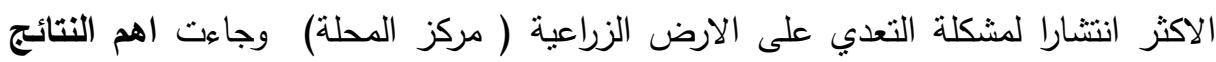
على النحو التالى: • لا توجد علاقة بين مستوى معرفة المبحوثين بالمتغيرات الاقتصادية وإقامة المبنى المخالف

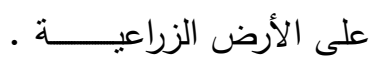

ارتفاع مستوى معرفة المبحوثين بالمتغيرات الاجتماعية وكذللك تأثيرها على قرار البناء

$$
\text { المخالف على الأرض الزراعية. }
$$

توجد علاقة بين المتغيرات المستقلة المرنبطة بالتعدي بالبناء على الأرض الزراعية.

\section{الإسار اللنظيه السرواســ}

( ) المادية التاريخية: نرتبط الماديبة التاريخية بتوصيف التغير الاجتماعى فى دول العالم

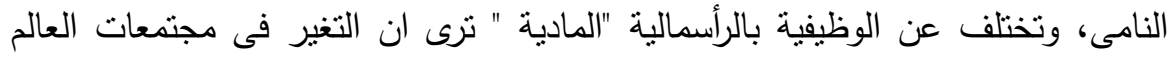

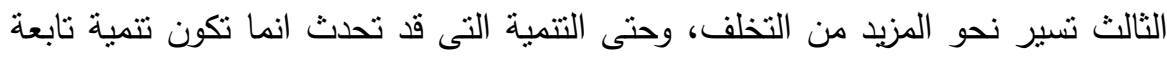

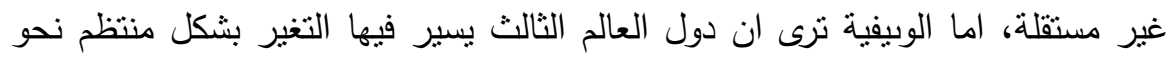
تحقيق النوذج المثالى للمجتمعات الغربية. 
ان البناء الاجتماعى بدول العالم الثالث هو بناء متخلف تابع محكوم بنمط لنقسيم العمل

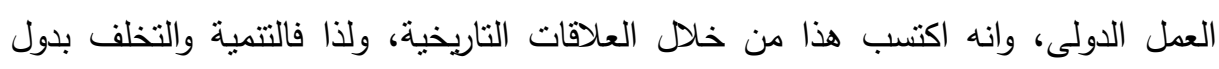
العالم الثالث انما هو وجهان لعملة واحدة، والذى لحق به الضرر الاكثر القرى التى زادت اكثر

وفى ضوء ذللك يكون فهم وتحليل التغير الاجتماعى فى دول العالم النامى من خلال

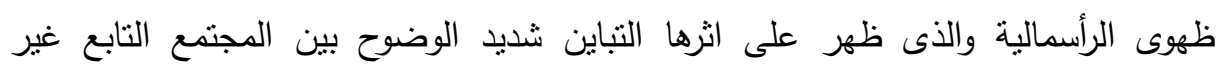

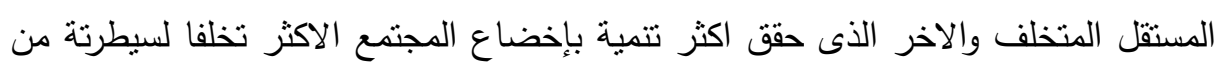

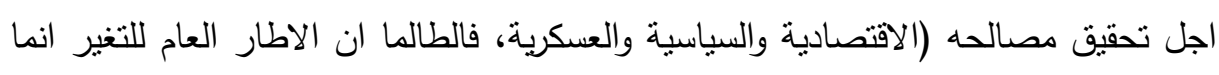
هو تغير تابع وغير مستقل حتما سيظل التغير بدول العالم الثالث تغيرا مشوها ليخلق ريفا

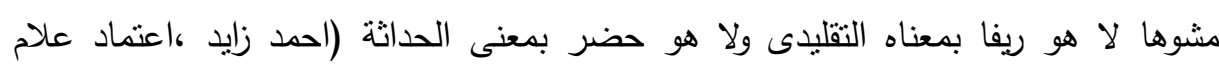
(09, r... T: r) النظرية البنائية الوظيفية: تعد إحدى النظريات الاجتماعية الني تحاول شرح وتقسير الظواهر الاجتماعية من خلال المماثلة التي يقيمها بارسونز بين النسق الاجتماعي والكائن العضوي، حيث يقول أن الحياة الاجتماعية هي كائن حي من نوع خاص، الفئ والفكرة القائلة أن الحياة الاجتماعية هي نظام اجتماعي أب نظام من أجزاء مختلفة تفسر الجزء البنائي

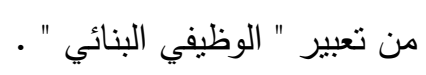

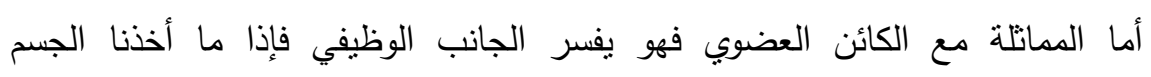

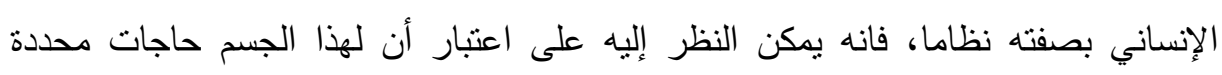
كالطعام مثنا ، ويتكون من عدد من الأجزاء المترابطة (الجهاز الهضمي، الإنهان المعدة والأمعاء

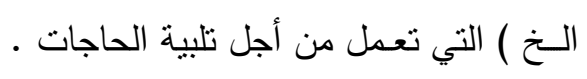

وتعتبر نظرية البنائية الوظيفية أحد الموجهات النظرية التى وجهت التهات الدراسة الراهنة

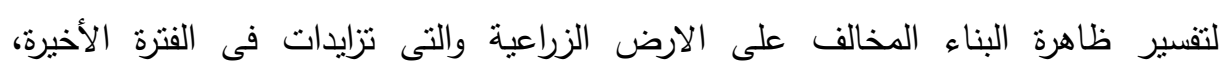

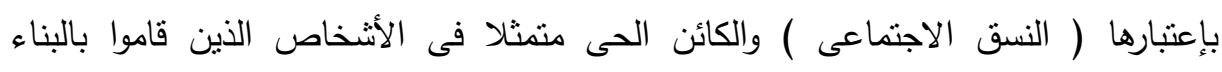

$$
\text { المخالف على الأرض الزراعية. }
$$




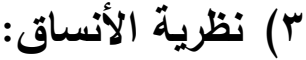

نظرية النسق الإيكولوجى: فالنسق الايكولوجى الذى يركز على العلاقة بين الإنسان والطبيعة

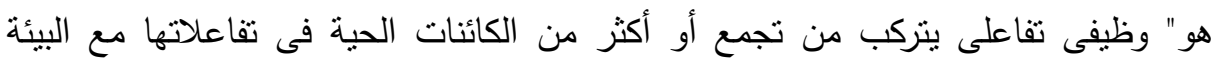
الفيزيقية والبيولوجية.

كما تهتم نظرية النسق الايكولوجى بالوظائف التى تؤديها الأجزاء لبعضها البعض ، وهذا

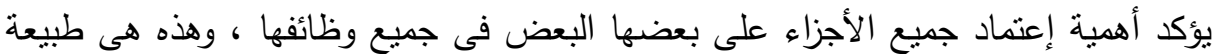

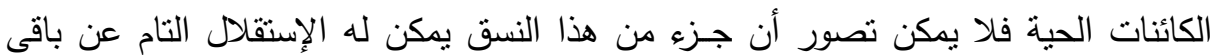

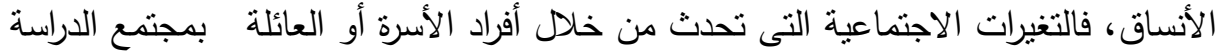

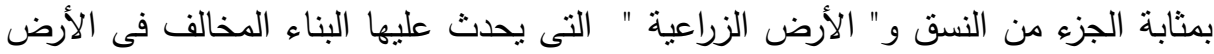
الزراعية بمثابة النسق الأكبر الذى ينتكل منه النسق الإيكولوجى للقرية ، وبمعنى آخر أنه النهاء

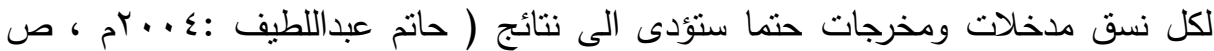

\section{الإجباءاهي المنهجية للسواسمة}

نوع الدراسة والمنهج والأدوات المستخدمسة: تنتمي هذه الدراسة إلى الدراسات الوصفية

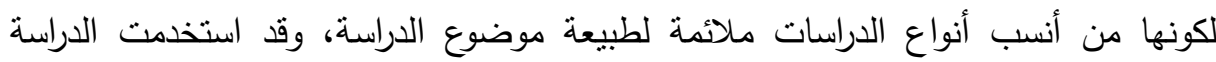

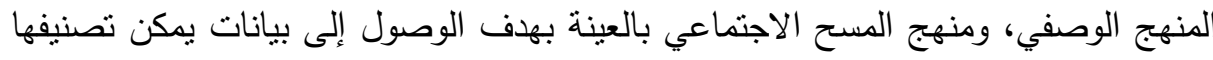

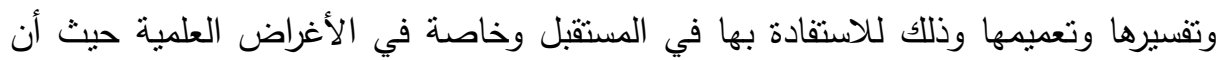
الدراسات الوصفية توفر صورة دقيقة ومحددة لظاهرة ما في المجتمع ولذلك استعانت الدراسة الكانة

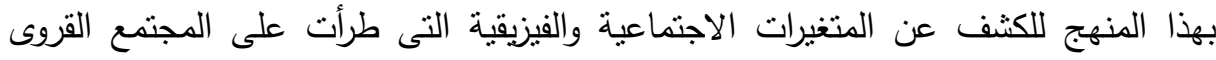

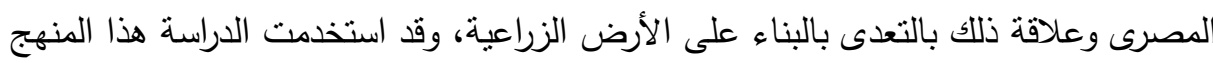

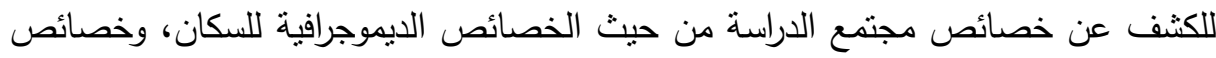

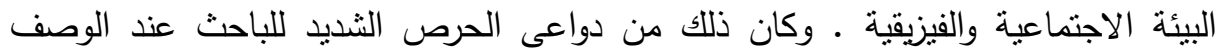

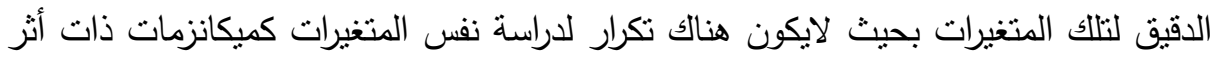
في مشكلة البناء على الأرض الزراعية. 


\section{الأدوات التي استخدمتها الدراسة هي:}

• استمارة استيان مكونة من أربعة محاور رئيسية، فضلا عن البيانات الأساسية ومكونة

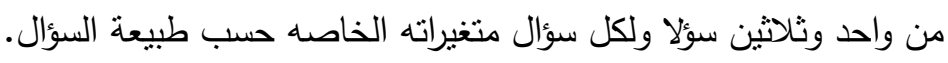

• • مقابلات مفتوحة مع مدراء الجمعيات الزراعية من خلال (دليل الدابل الدابلة).

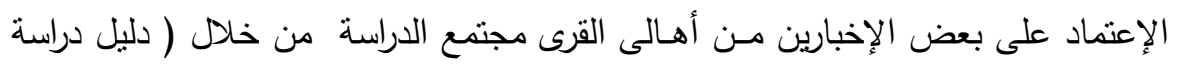

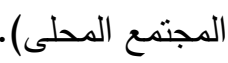

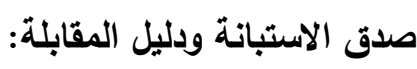

صدق الاستبانة: ويعنى أن تقبس الاستبانة ما وضعت لقياسه (حسين عطيفة : r...r.

( r9o

الصدق الظاهرى: فقد نم حساب صدق الاستبانة عن طريق:صدق المحكمين (الصدق

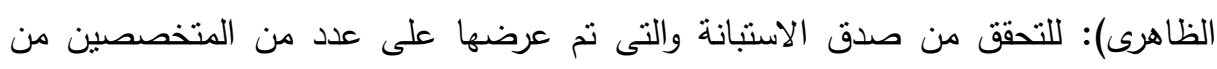

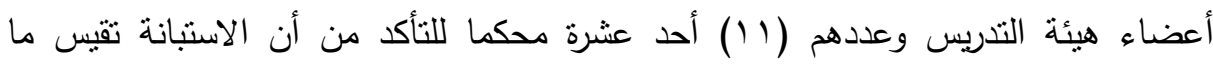

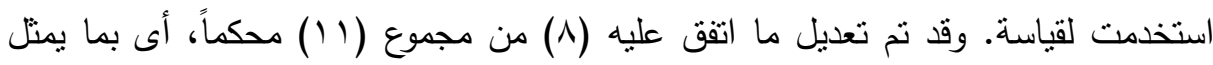
نسبة اتفاق (•^\%\%) من المحكمين.

ايضا تم حساب الصدق الذانى للاستبانة وهذا سيتضح فى أثناء عرض الثنات للاستبانة وكان مؤشر صدق الاتساق الداخلى: من خلال ارتباط درجة كل مفردة بالدرجة الكلية للمحور

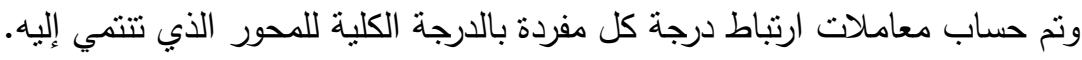

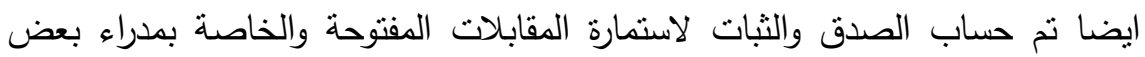

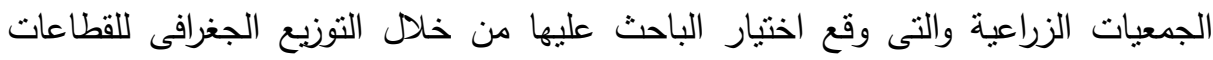

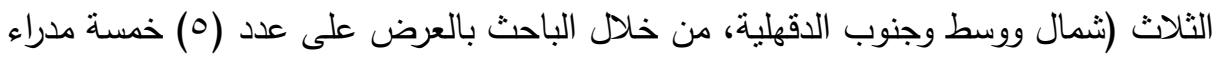

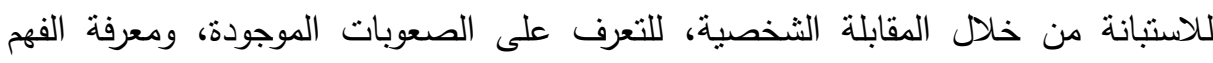

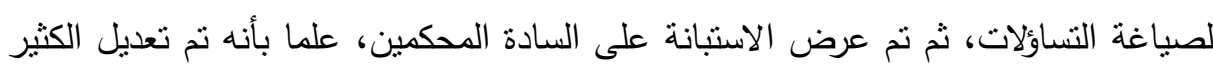

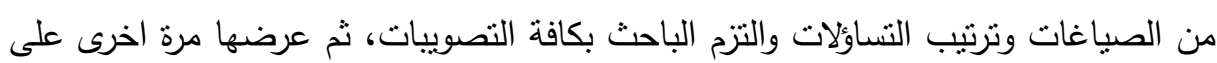

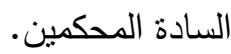


ولقد استعانت الدراسة بطريقة الإحصاء الألية بإدخال قاعدة البيانات على الحاسب الألى من خلال برنامج : (spss)، نم عرض البيانات فى ضوء جداول تكرارية والنسبة المئوية.

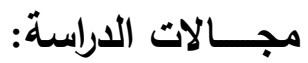
المجال البشري وطريقة اختيار العينة: بعض قرى محافظة الدقهلية والمنتشر بها ظاهرة البناء

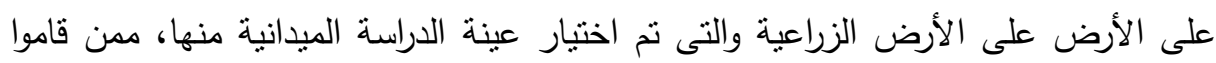

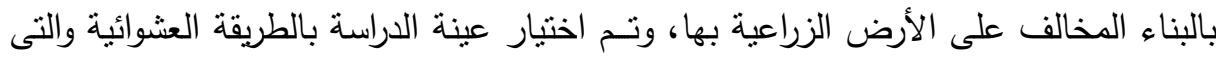

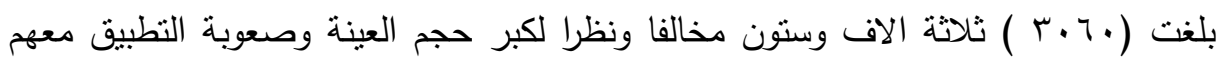

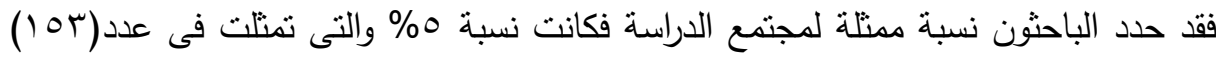

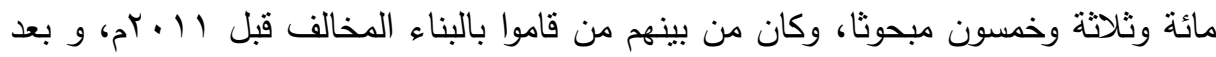

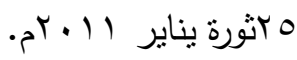
المجال الجغرافي: يقصد به المنطقة التى اجريت بها الدراسة الميدانية والتى نم تحديدها

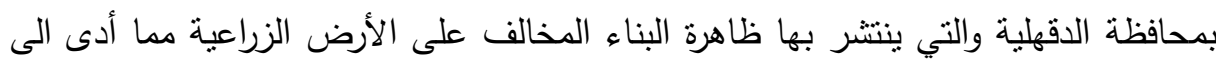
إإنكماش الأرض الزراعية بشكل ملحوظ، ولذلك تم إختيار عدد (7) مراكز من خلال تقسيم المحافظة الى ثلاث قطاعات وهى ( شمال، ووسط، وجنوب الدقهلة ) بحيث يمكن تمثيل مجتمع الدراسة جغرافيا ما هو موضح بالجدول التالى: 
عاليه حلمي عبد العزيز وآخرون

\begin{tabular}{|c|c|c|c|c|c|c|c|c|}
\hline الجمالي & المئوية • النسبة \% & القرى & 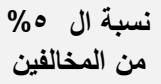 & المخالفين & المركز & القرية & القطاع & p \\
\hline \multirow{3}{*}{$\leq 7$} & \multirow{3}{*}{ r } & \multirow{3}{*}{ ov } & 11 & rrq & \multirow{3}{*}{ اجا } & ديرب بقطارس & \multirow{7}{*}{ الجنوبي } & \\
\hline & & & 9 & $1 \wedge \varepsilon$ & & صهرجت & & 1 \\
\hline & & & To & $0 .$. & & طنامل & & \\
\hline \multirow{3}{*}{01} & \multirow{3}{*}{$r$} & \multirow{3}{*}{ or } & 19 & rVT & \multirow{3}{*}{ ميت غمر } & دماص & & \multirow{3}{*}{ r } \\
\hline & & & r. & $\sum I V$ & & ميت ابو خالد & & \\
\hline & & & 19 & rar & & دنديط & & \\
\hline ir & 1 & r) & ir & $T \leqslant 1$ & الامديد & كفر الامير & & r \\
\hline 1. & 1 & $T \varepsilon$ & 1. & Y.. & طلخا & المنيل & \multirow{4}{*}{ الوسط } & $\varepsilon$ \\
\hline \multirow{3}{*}{17} & \multirow{3}{*}{ r } & \multirow{3}{*}{ or } & $r$ & $\leq 0$ & \multirow{3}{*}{ المنصورة } & تلبانه & & \multirow{3}{*}{0} \\
\hline & & & 0 & Vo & & الخيارية & & \\
\hline & & & 1. & IAr & & البقلية & & \\
\hline \multirow{2}{*}{11} & \multirow{2}{*}{ r } & \multirow{2}{*}{ ro } & $\varepsilon$ & 90 & \multirow{2}{*}{ بلقاس } & الروضــــة & \multirow{2}{*}{ الثمالي } & \multirow{2}{*}{7} \\
\hline & & & v & IrV & & الستامـــنى & & \\
\hline 104 & 15 & TrV & 104 & r.T. & & L & الإج & \\
\hline
\end{tabular}

المجال الزماني: للاراسة الميدانية: اعتبارا من يونيو 0 • بrم حتى: نهاية ديسمبر 0 • بrم

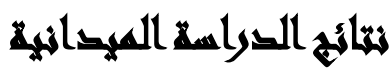

الفرض الأول: ينص الفرض على أنه توجد علاقة دالة إحصائياً بين الأبناء الذكور وحجم

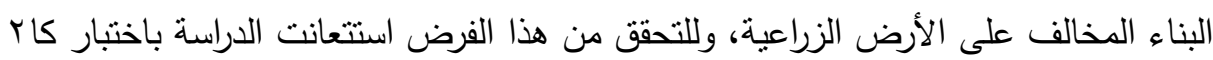
للاستقلالية. Independence ، وذلك بنطبيق المعادلة الآتية: ( $(\vec{a})$

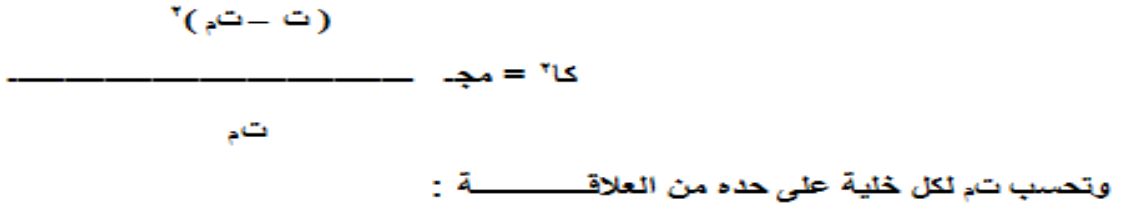

مجموع الصف × مجموع الثعمود

المجموع الكثى (1) (عدو الأن

مع العلم بأن درجات الحرية في هذه الحالة = (عدد الصفوف - 1) (عدد الأعمدة - 1)

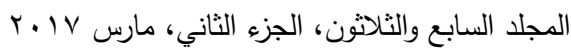


جدول(1): نكرارات الأبناء الذكور فى أسرة المخالف وعلاقتها بحجم البناء الدخالف على الأرض الزراعية وقيمة كاب ودرجات الحرية ومستوى الدلالة

\begin{tabular}{|c|c|c|c|c|c|c|c|c|}
\hline 牙 & 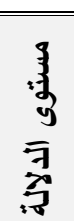 & $\frac{3}{3}$ & & 可. & : & 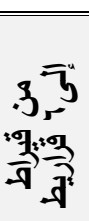 & : & /البزأراعلية \\
\hline \multirow{4}{*}{ دالة } & \multirow{4}{*}{$\cdot, \cdot 0$} & \multirow{4}{*}{$\varepsilon$} & \multirow{4}{*}{$1 \cdot, 17}$. & IY. & 1. & $\overline{T V}$ & $\overline{V T}$ & من \\
\hline & & & & TY & 0 & 1. & TV & منك إلى \\
\hline & & & & 1 & 1 & $=$ & $=$ & اكتز من \\
\hline & & & & 104 & 17 & $\varepsilon V$ & 9. & المجموع \\
\hline
\end{tabular}

يتضح من نتائج الجدول السابق أنه" توجد علاقة دالة إحصائياً بين الأبناء الذكور فى ألى أسرة المخالف وحجم البناء المخالف على الأرض الزراعية، حيث بلغت قيمة كاب للاستقلالية

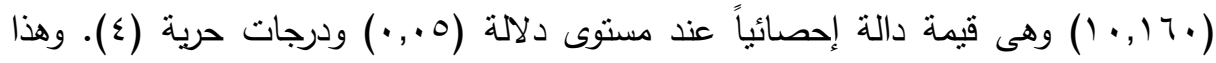
يعنى أن هناك فروق بين الأسر الدختلفة من حيث عدد الذكور فيها بالنسبة للبناء على الأرض الزراعية، حيث يتضح أن الأسر التى يتراوح عدد الذكور فيها من( (1 - r) أكثر بناءا على مساحة أقل من قيراط وزيادة عدد المساحات (حلالت التعدى ) التى تم البناء عليها

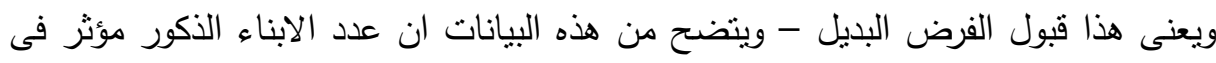

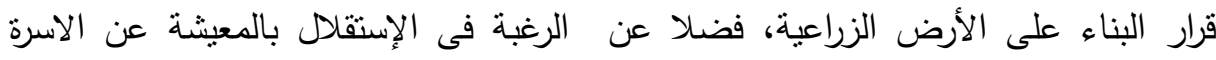

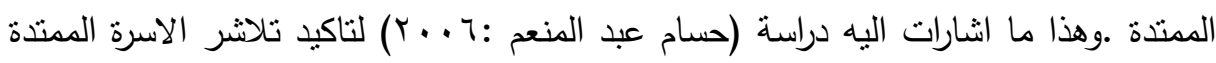

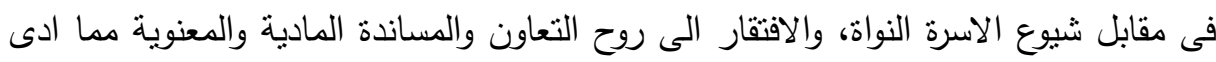

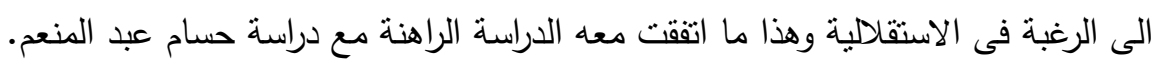
الفرض الثانى: ينص الفرض على أنه " توجد علاقة دالة إحصائياً بين الابناء الإناث وحجم البناء المخالف على الأرض الزراعية ". للتحقق من هذا الفرض فقد استخدم الباحث اختبار كاب للاستقلالية Independence 
جدول(ץ): تكرارت الأبناء الإناث فى أسرة المخالف وحجم البناء المخالف على الأرض

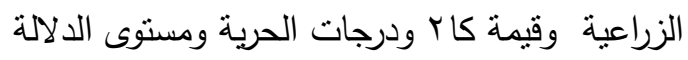

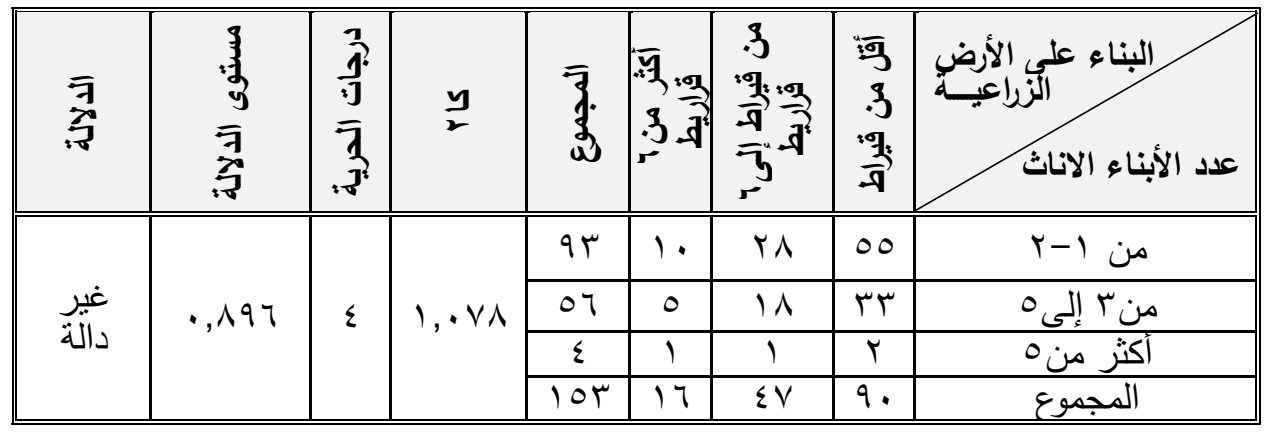

يتضح من نتائج الجدول السابق أنه لا نوجد علاقة دالة إحصائياً بين الابناء الإناث في أسرة المخالف وحجم البناء المخالف على الأرض الزراعية، حيث بلغت قيمة كاب لاستقالالية

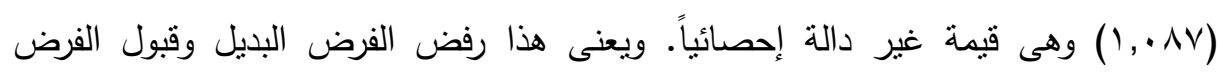

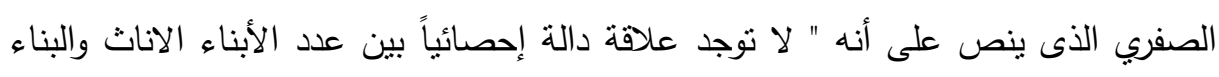
المخالف على الأرض الزراعية " ويتضح من هذه البيانات ان السبب فى الاقدام على البناء

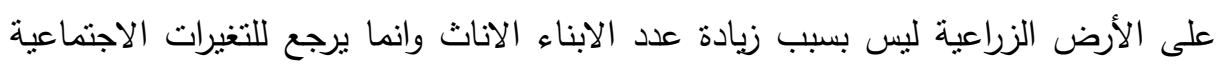

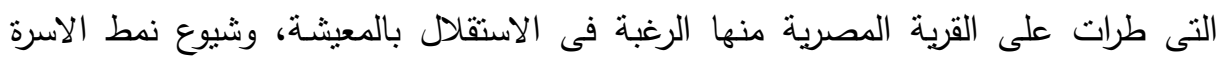
النواة.

الفرض الثالث: بنص الفرض على أنه " نوجد علاقة دالة إحصائياً بين نوقيت البناء وحجم البناء المخالف على الأرض الزراعية ". Independence للتحقق من هذا الفرض فقد استخدم الباحث اختبار كاب للاستقلاءلية لألية 
جدول(r): تكرارت نوقيت البناء والتعدى على الأرض الزراعية وقيمة كاب ودرجات الحرية ومستوى الدلالة المالة

\begin{tabular}{|c|c|c|c|c|c|c|c|c|}
\hline 亏 & 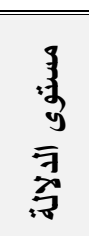 & $\frac{3}{3}$ & $y$ & 亦. & 可 & 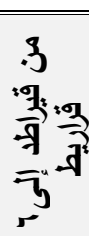 & 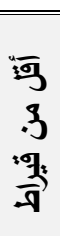 & / التعلى الأرض \\
\hline \multirow{3}{*}{ غير } & \multirow{3}{*}{$\cdot, 110$} & \multirow{3}{*}{ r } & \multirow{3}{*}{$r, r \vee \wedge$} & v) & 0 & 19 & $\varepsilon V$ & قبل عام I| + بام \\
\hline & & & & Ar & 11 & ru & $\varepsilon r$ & بعدهب يناير || |+rم \\
\hline & & & & 10 & 17 & $\varepsilon V$ & 9. & المجموع \\
\hline
\end{tabular}

يتضح من نتائج الجدول السابق أنه لا توجد علاقة دالة إحصائياً بين توقيت البناء المخالف والتعدى على الأرض الزراعية؛ حيث بلغت قيمة كاب للاستقلالية (r,rV^) وهى قيمة غير دالة إحصائياً. ويعنى هذا رفض الفرض البرضيل البديل وقبول الفرض الصفرى الذى ينص

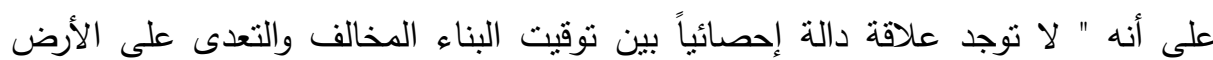

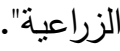

كما بتضح انه لا توجد فروق جوهرية بين توقيت البناء المخالف على الارض الزراعية

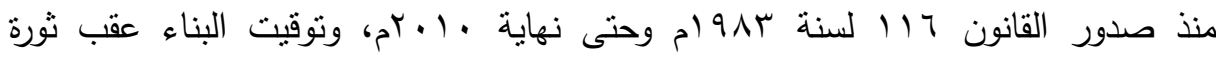
الخامس والعشرين من يناير |l أبم ، فى حجم التعديات بالبناء المخالف على الارض

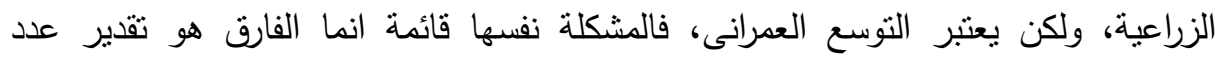
المخالفات فى ظل ظروف معينة منها ثورة مب يناير خلال فترة وجيزة نم التعدى على اكثر من مليون فدان تقريبا بمحافظة الدقهلية مجتمع الدراسة (تجميع الباحث من خلال الادارات الزراعية بالدقهلية ).

الفرض الرابع: ينص الفرض على أنه " توجد علاقة دالة إحصائياً بين ملكية الأرض

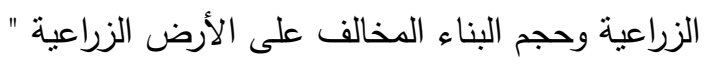

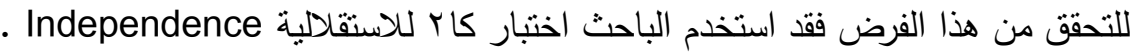


جلول(؛): تكرارت ملكية الارض الزراعية وحجم البناء المخالف على الأرض الزراعية وقيمة

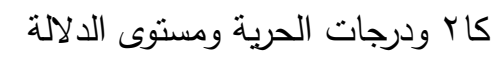

\begin{tabular}{|c|c|c|c|c|c|c|c|c|}
\hline 牙 & 雪示 & 高: & $\frac{y}{2}$ & $\begin{array}{l}\overline{3} \\
\text { a }\end{array}$ & 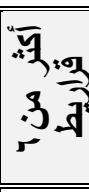 & $\frac{3}{2}=3$ & 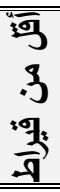 & حجم الملكية على الأرضيّة \\
\hline \multirow{5}{*}{ دالة } & \multirow{5}{*}{$\cdot, \cdot 1$} & \multirow{5}{*}{7} & \multirow{5}{*}{ rA, rYA } & זי & $r$ & ז & $r \varepsilon$ & من قيراط الى اقل من \\
\hline & & & & 0. & $\wedge$ & r & rq & لا يمنلاك ارضاً على الاطلى \\
\hline & & & & ro & $r$ & 17 & 17 & من ا إلى أقل من \\
\hline & & & & 0 & $r$ & $r$ & 1 & من ه إلى آقلّ من • \\
\hline & & & & 104 & 17 & $\varepsilon V$ & 9. & المجموع \\
\hline
\end{tabular}

يتضح من نتائج الجدول السابق أنه نوجد علاقة دالة إحصائياً بين حجم الملكية ومساحة

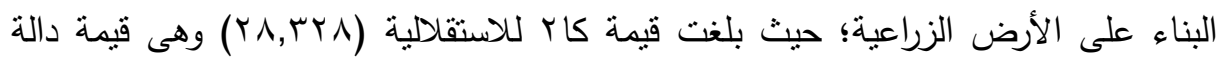

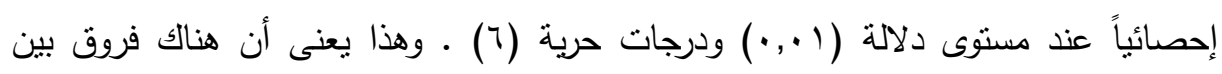

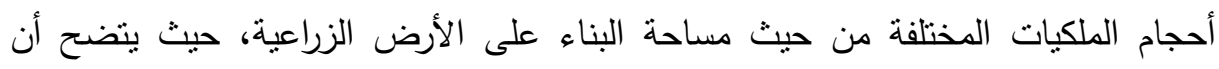

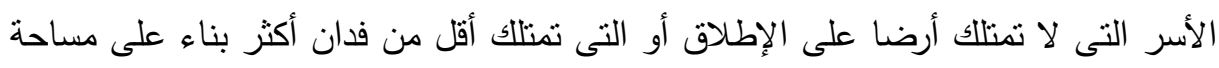

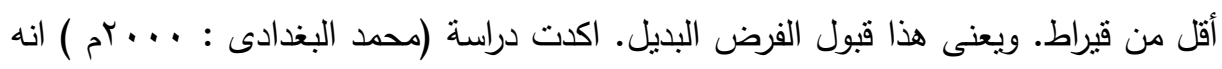
لا توجد فروق جوهرية بين حجم الحيازة ومتوسط الانتاجية للفدان فى مختلف الاحجام والنظم

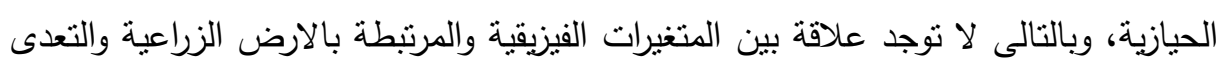

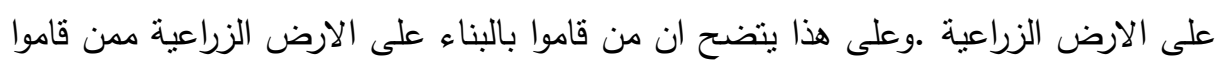

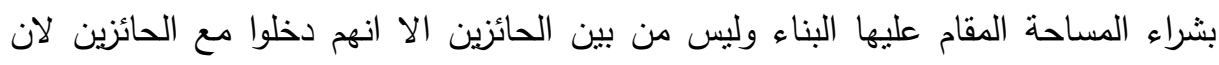

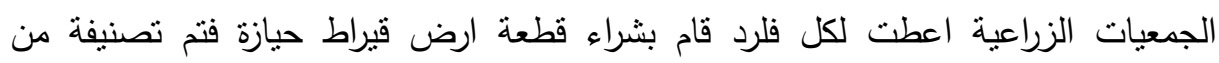
الحائزين. الفرض الخامس: ينص الفرض على أنه " توجد علاقة دالة إحصائياً بين نمط الأسرة وحجم البناء المخالف على الأرض الزراعية ". للتحقق من هذا الفرض فقد استخدم الباحث اختبار كاب للاستقلالية Independence. 
جدول(؛) ): تكرارت نمط أسرة المخالف وحجم البناء المخالف على الأرض الزراعية وقيمة كاب ودرجات الحرية ومستوى الدلالة

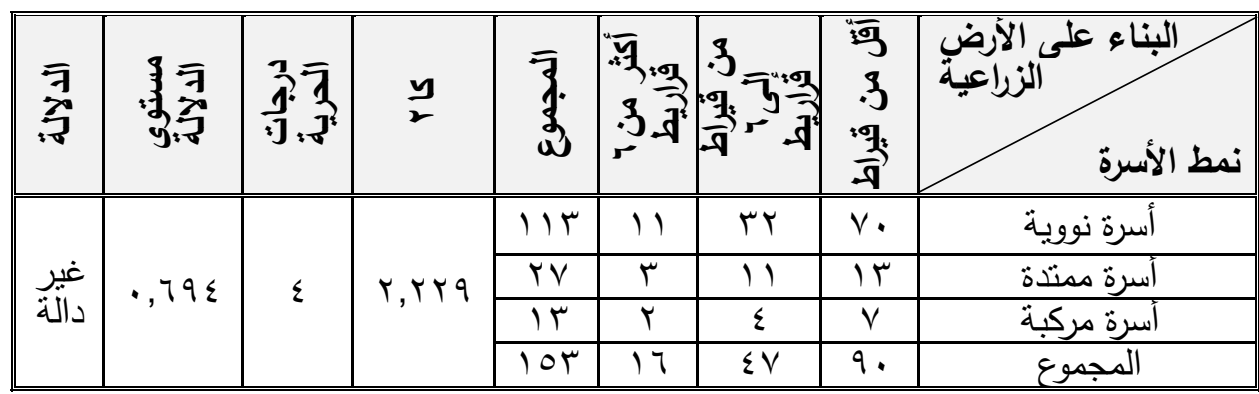

بتضح من نتائج الجدول السابق أنه لا توجد علاقة ارتباط دالة إحصائياً بين نمط الأسرة

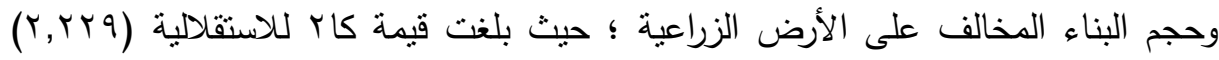
وهى قيمة غير دالة إحصائياً. ويعنى هذا رفض الفرض البديل وقبول الفرض الصفرى الذى

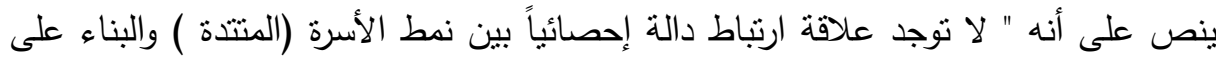

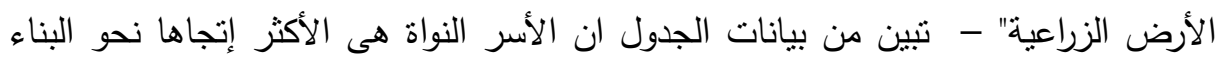

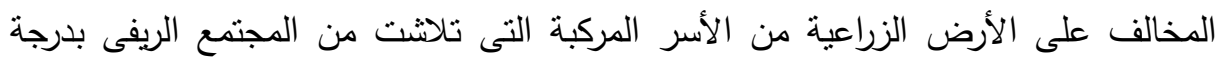

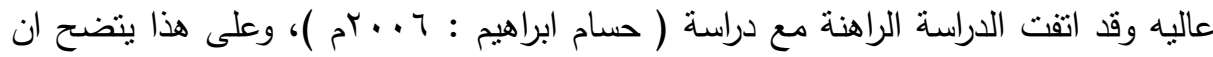

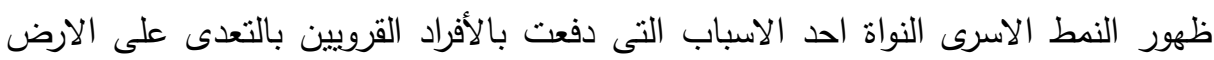

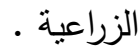
الفرض السادس: ينص الفرض على أنه " نوجد علاقة دالة إحصائياً بين المستوى التعليمى وحجم البناء المخالف على الأرض الزراعية ". للتحقق من هذا الفرض فقد استخدم الباحث اختبار كاب للاستقلالية Independence 
جدول(ه): تكرارت المستوى التعليمى وحجم البناء المخالف على الأرض الزراعية وقيمة كاץ

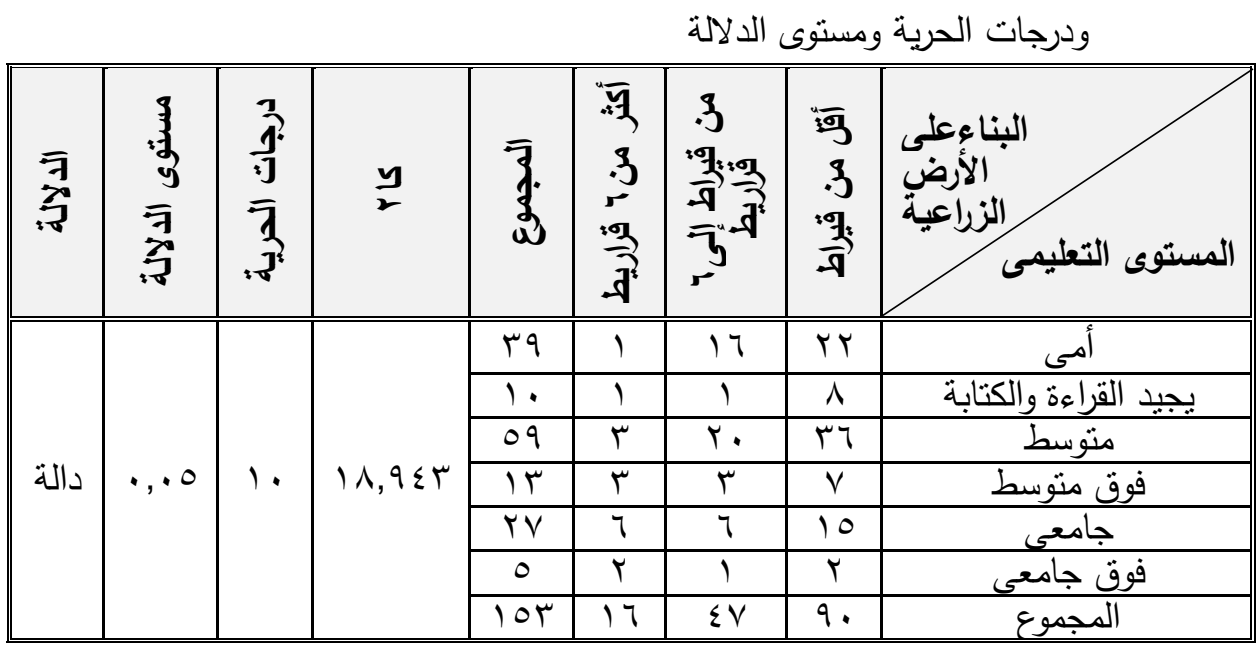

يتضح من نتائج الجدول السابق " أنه توجد علاقة دالة إحصائياً بين المستوى التعليمى التهى

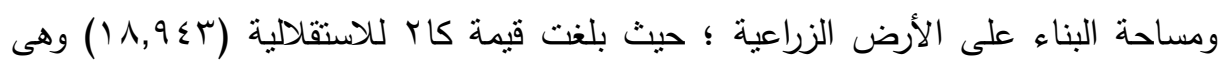

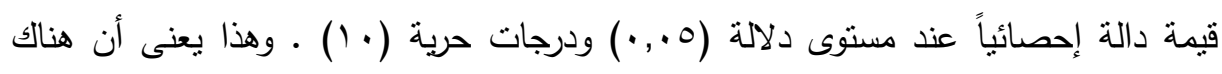

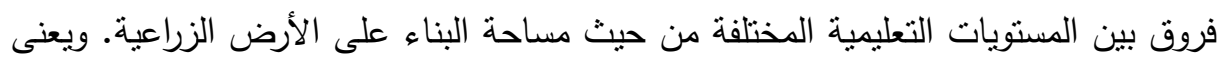

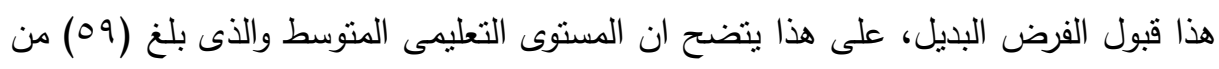

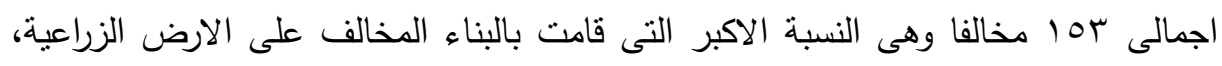
وقد يرجع ذللك للمستوى التعليمى، وايض يعود لارتفاع المستوى الاقتصادى بسبب اذدواج

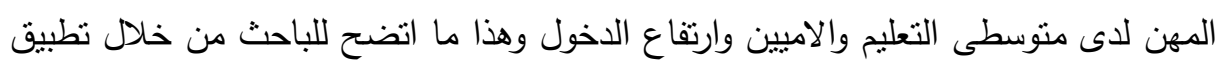
الاستبان شخصيا . الفرض السابع: ينص الفرض على أنه " توجد علاقة دالة إحصائياً بين صعوبة إستخراج تراخيص البناء داخل الكنلة السكنية وحجم البناء المخالف على الأرض الزراعية " . للتحقق من هذا الفرض فقد استخدم الباحث اختبار كاب للاستقلالية Independence 
جدول(V): تكرارت صعوبة استخراج التراخيص داخل الكتلة السكنية وعلاقتها بحجم البناء المخالف على الأرض الزراعية وقيمة كاب ودرجات الحرية ومستوى الدلالة

\begin{tabular}{|c|c|c|c|c|c|c|c|c|}
\hline 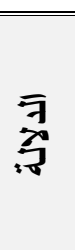 & $\begin{array}{l}3 \\
3 \\
3 \\
\overline{3} \\
\text { 亏7 }\end{array}$ & $\begin{array}{l}3 \\
\overline{3} \\
\overline{3} \\
\overline{3}\end{array}$ & $\frac{y}{2}$ & $\begin{array}{l}\overline{3} \\
\text { s. }\end{array}$ & 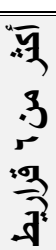 & 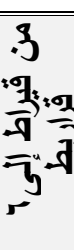 & 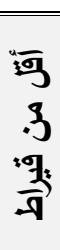 & 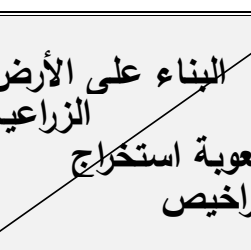 \\
\hline \multirow{3}{*}{ غالثة } & \multirow{3}{*}{$\cdot, \wedge \leqslant 1$} & \multirow{3}{*}{ r } & \multirow{3}{*}{$\cdot, r \leqslant 0$} & 17 & 1 & 0 & 1. & توجد صعوبة \\
\hline & & & & $I \mu V$ & 10 & $\varepsilon Y$ & A. & لا توجد صعوبة \\
\hline & & & & 104 & 17 & $\sum V$ & 9. & المجموع \\
\hline
\end{tabular}

بتضح من نتائج الجدول السابق أنه لا نوجد علاقة دالة إحصائياً بين صعوبة استخراج الثراخيص ومساحة البناء على الأرض الزراعية؛ حيث بلغت قيمة كاب للاستقلالية (0 ؟ . •)

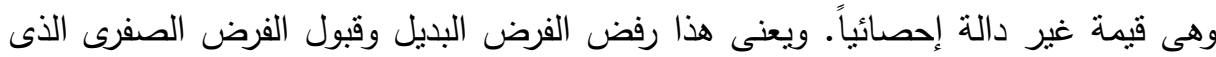
ينص على أنه " لا نوجد علاقة دالة إحصائياً بين صعوبة استخراج التراخيص ومساحة البناء على الأرض الزراعية"، وعلى هذا قد يرجع ذللك لتعقد الاجراءات وصعوبتها لاستخراج التراخيص الخاصة بالبناء داخل الكتلة السكنية وايضا المتخلات، اما ماجاء بالاجابات كان نتيجة التخوف الثديد من الجهات المسئولة عن حماية الاراضى الزراعية من قبل المخالفين وهذا ايضا ما اتضح للباحث بحكم انه يقطن احدى قرى مجتمع الدراسة كما جاء فى احد تعبيرات بعض المبحوثين " لحسن يهدوا لنا البيت خلينا ساكتين ".

\section{الميوكيامي}

• تحديد الاختصاصات والمسئولية بشكل أكثر تحديدا وصراحة فى القانون للقائمين على حماية الأرض الزراعية للحد من التعدى على الأرض الزراعية.

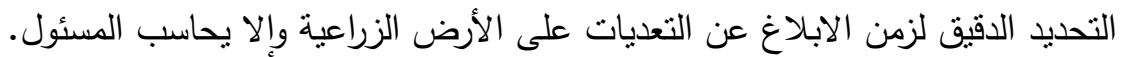
• مراجعة إجراءات ( القانون 119 البناء الموحد ) ومدى تطبيقة فى الريف وعلاقته بمشكلة البناء المخالف على الارض الزراعية. 
تقنين قكرة بناء المساجد أو المستوصفات الخيرية على الأراضى الزراعية من خلال

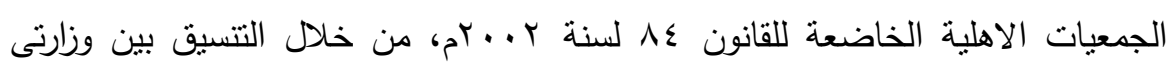
التضامن الاجتماعى والزراعة.

تكليف شرطة متخصصة أسـوة بشرطة المرافق-شرطة الكهرباء- شرطة السياحة ..الخ الخهاء لحماية الأراضى الزراعية وتكون عبارة عن جهاز مكون من الثرطة، ومسئول حماية

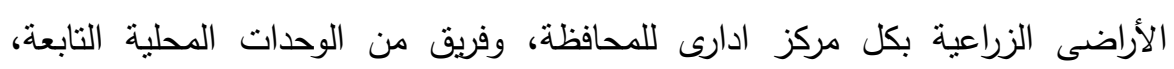
ومجلس المدينة لمراقبة حالات التعدى على الارض الزراعية وضبطها فى الحال.

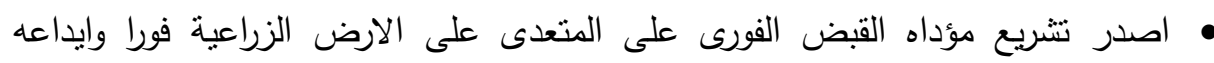

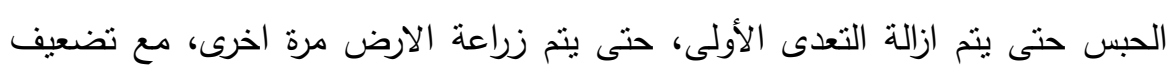

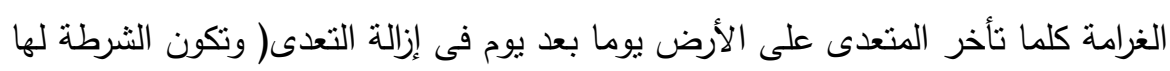

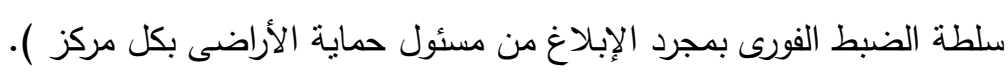

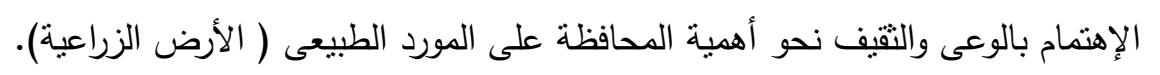

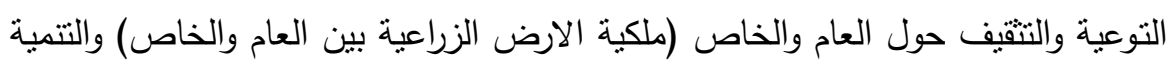
المستدامة. التوسع الجاد نحو إعمار الظهير الصحراوى بحيث يكون جاذبا للهجرة الى قرى الظهير الصحراوى بشرط توفير الخدمات والمرافق (نموذج القرى المماثلة ).

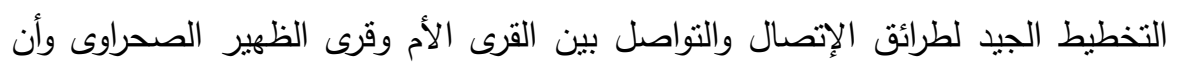

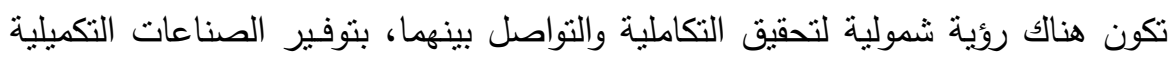
بالقرى الجديدة لخدمة القرى الأم ووسائل المواصلات الجيدة.

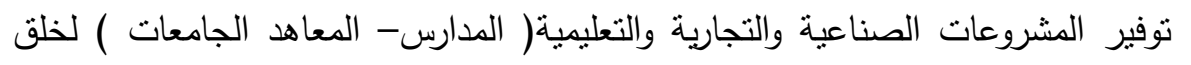
فرص عمل وتيسير عوامل الجذب للمجتمعات الجدية. •تشديد العقوبات وسرعة البت فى المخالفات كان يحدد القانون المخالفة والعقوبة الرادعة القابلة للتطبيق والتى بصعب فيها التحايل على القانون بالقانون. 


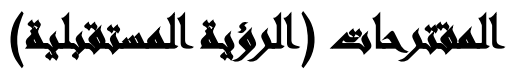

المسار الأول: فى حال تبنى الدولة لخطة أو برنامج إنمائى حقيقى يعالج المتغيرات

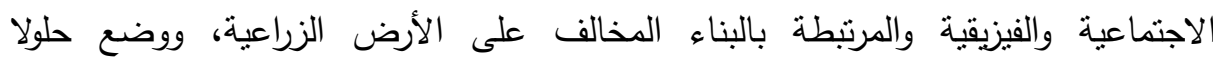

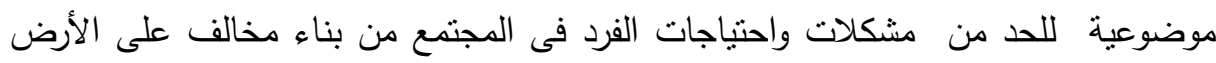

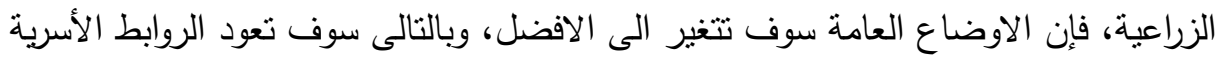

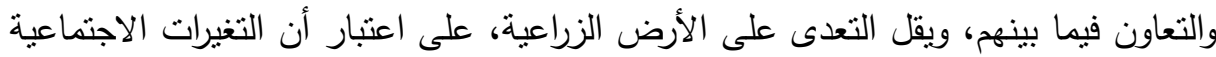

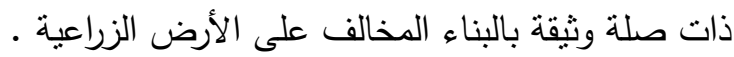

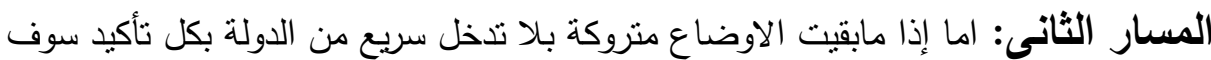

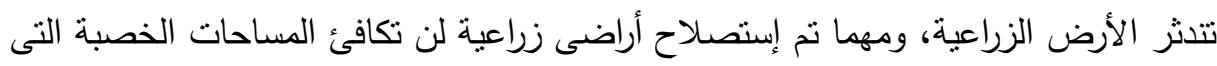

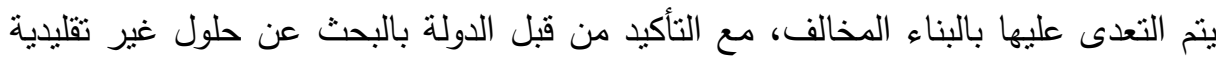

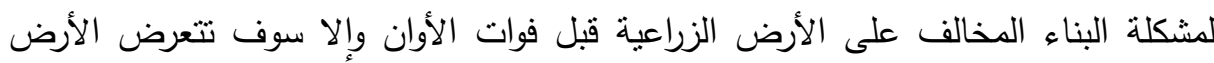

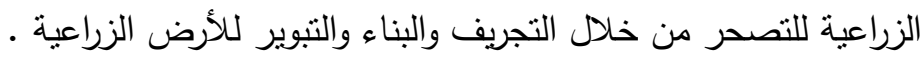
المسار الثالث: اجراء المزيد من الدراسات وبإستمرار للمتغيرات الاجتماعية نظرا لأن التغير الاجتماعى دائم ومستمر بالمجتمعات فى ظل الانفتاح المعلوماتى التكنولوجى " دور الانفتاح

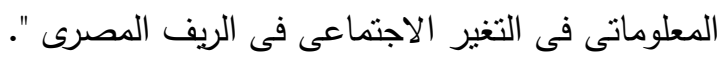

\section{خائمة المرايجة}

أحمد زايد، اعتماد محمد علام (^ . . rم): التغير الاجتماعى، مكتبة الانجلو المصرية

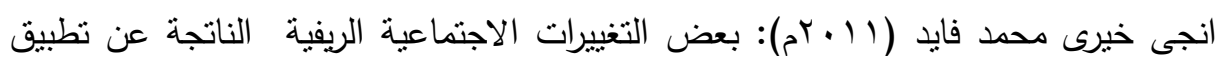

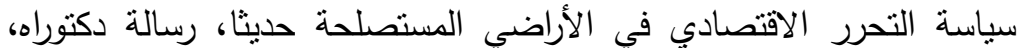

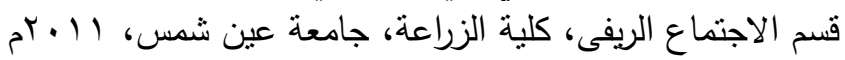

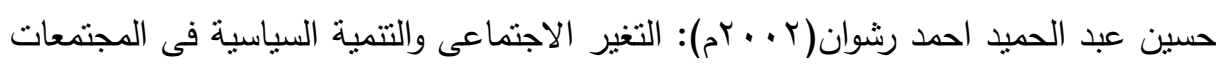
النامية، ط بالمكتب الجامعى الحديث، الأسكندرية الأنية 
حسين ابو الفتوح عطيفة (r + . rم): منهجية البحث العلمى وتطبيقاتها فى الدراسات التربوية والنفسية، القاهرة، دار النشر الجامعى : النه

السبد عبد العاطي، محمد أحمد بيومى(0 . . ؟): علم الاجتماع الثقافى، دار المعرفة الجامعية الازاريطة، الاسكندرية أحمد بية

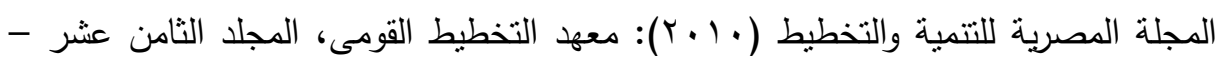
العدد الاول يونيه

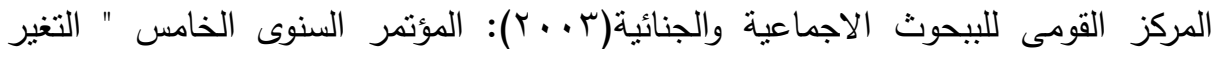

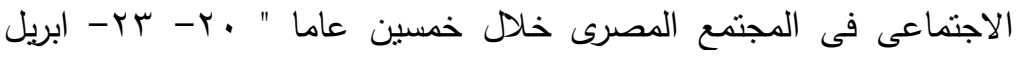

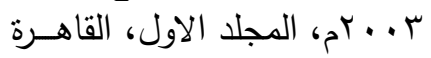

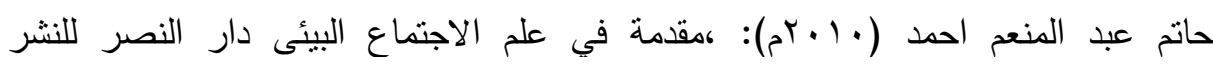
والتوزيع، القاهرة الهد

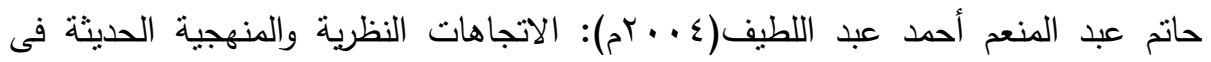

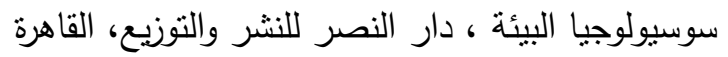

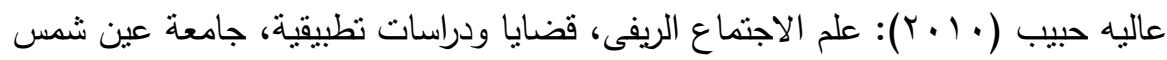

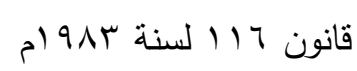

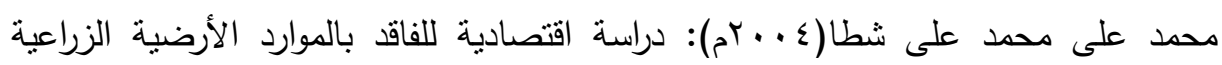

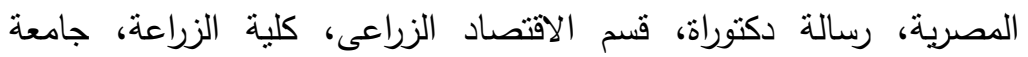
المنصورة

محمد عاطف غيث(970 (1): التغير الاجتماعي في المجتمع القروي ،دراسة فى محافظة الدقهلية " القيطون وهلا وكفر الثيخ "الأنير " الدار القومية للطباعة والنشر ، الاسكندرية

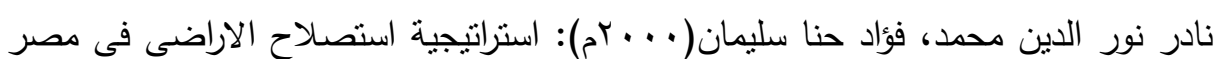

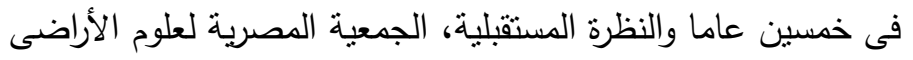


مجلة العلوم البيئية

معهذ الدراسات والبحوث البيئية - جامعة عين شمس البئ

\title{
SOCIAL AND PHYSICAL ENVIRONMENT \\ VARIABLES ASSOCIATED WITH BUILDING ON \\ AGRICULTURAL LAND \\ A FIELD STUDY ON SOME VILLAGES IN AL- \\ DAQAHLYIA GOVERNORATE
}

\author{
Habib, Aalyia, H. A. ${ }^{(1)}$; AL- Nanna, M. A. ${ }^{(2)}$ \\ and Ahmed, Y. M. M. ${ }^{(3)}$
}

1) Faculty of Girls, Ain-Shams University .2) Faculty of Agriculture, Ain Shams University. 3) Dakahlia Directorate of Social Solidarity

\begin{abstract}
The study aims to recognize the variables of the social and physical environment associated with the inconsistent building on the agricultural land, which happening to the Egyptian village, determining the reasons that make the farmer have an inconsistent building on the agricultural land; moreover, the study aims to recognize the effects resulting because of the inconsistent building on the agricultural land. In order to achieve the goals of the study the researchers have organized the study in two chapters: the first deals with the reference and theoretical study of the most previous studies, on the other hand the second one deals with the field procedures and studies and the study of the local society of some villages in Dakahlia governrate.

In order to achieve the goals, the researcher has divided the society into three sectors: (north, middle and south) so that the sample can be greatly resembling to the society, this study depended on the descriptive and social survey curriculum and the curriculum of the local society study, in addition to that this study has appealed for some tools to get some field information including: (the questionnaire form, the deep encounter/meeting and the study of the local society index). The researcher has appealed for a 153 sample of the ones who have built


inconsistently on the agricultural land of 3060 total contradicting with the society of the study(some villages of Dakahlia governrate) representing $5 \%$ of the contravener and the number of the villages connecting with the study.

\section{The results of the study:}

1) There is a relation among the social changes(the living independence desire, education standard, income standard, and family standard) the most common on the study field and the inconsistent building on the agricultural land, resulting in $41.2 \%$ of the people who have less than an acre who have built inconsistently on the agricultural land; moreover, there are some who don't own a land at all representing $32.7 \%$ have also built inconsistently on the agricultural land, which means that ownership is not a condition not to stop or the inconsistent building on the agricultural land.

2) There is no relation between the physical environment changes and the inconsistent building on the agricultural land, despite the increase of the acre production, constructing on the agricultural land is increasing gradually.

3) There is no statistics including (males, females) in the family and the inconsistent building on the agricultural land.

4) There is dominance of $73.9 \%$ of the nuclear family in the villages of Dakahlia governrate, on the other hand $17.6 \%$ of the extended family matching with many previous studies.

5) There is no statistics including the number of the children (male, female) of the family and the inconsistent building on the agricultural land.

There are no differences of a statistic reference (0.01) between the rural society and the civilized rural one according to the type and the style of the inconsistent building on the agricultural land.

6) The study recommends that there has to be a serious intervention from the country to find unconventional solutions limiting the inconsistent building on agricultural land, otherwise Egypt is going to suffer from extreme desertification of its agricultural lands that is going to affect badly on the national income throughout the agricultural sector that represents the main income for Egypt as it is considered to be an agricultural country.

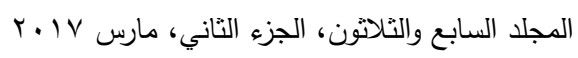

